\title{
Tracheostomy in Infants and Children
}

\author{
Karen F Watters MB BCh BAO MPH
}

\author{
Introduction \\ Patient Evaluation \\ Tracheostomy Tube Types \\ Tracheostomy Procedures in Pediatric Population \\ Physiological Consequences of Tracheostomy \\ Complications of Tracheostomy in Children \\ Decannulation in Infants and Children \\ Quality Improvement in Tracheostomy Care \\ Summary
}

\begin{abstract}
Over the last decade, tracheostomy has been increasingly performed in children, aligned with the improvements in neonatal and pediatric ICU care. Nowadays, the majority of children with tracheostomy represent a very complex cohort of patients with sustained reliance on tracheostomy and related medical technology for long-term survival. Tracheostomy is one of the most commonly performed procedures in the adult ICU. Contrary to adult practice, tracheostomy is a much less common procedure in the pediatric ICU, being performed in $<3 \%$ of patients. There is no definite consensus about the length of time a child should remain endotracheally intubated before the placement of a tracheostomy. Tracheostomy in children also continues to remain a predominantly surgical procedure, with percutaneous tracheostomy being performed infrequently and only considered feasible in older children. The indications, preoperative considerations, and procedure types for tracheostomy in children are reviewed. There is also a lack of consensus on an optimal pediatric decannulation protocol. The literature discusses a myriad of protocols that use varying combinations of in-patient/out-patient resources, specialized tests, and procedures An ideal decannulation protocol is presented, as well as review of recently published decannulation algorithms. Finally, children with tracheostomy have a higher risk of adverse events and mortality, which are largely secondary to their comorbidities rather than the tracheostomy. The majority of the tracheostomy-related events are in fact potentially preventable. There is a recognized need for improvement and coordination of care of pediatric patients with tracheostomy. A multidisciplinary coordinated approach to tracheostomy care has already shown promising results. This paper seeks to review the pertinent literature regarding quality improvement initiatives for tracheostomy care, including review of the recently established Global Tracheostomy Collaborative. Key words: tracheostomy; pediatric; decannulation; polysomnography; direct laryngobronchoscopy; capped; complications; outcomes; quality improvement collaborative; Global Tracheostomy Collaborative. [Respir Care 2017;62(6):799-825. (c) 2017 Daedalus Enterprises]
\end{abstract}

\section{Introduction}

Over the last decade, tracheostomy has been increasingly performed in children with complex and chronic conditions, for management of upper-airway obstruction, prolonged ventilation, abnormal ventilatory drive, and irreversible neuromuscular conditions. ${ }^{1-5}$ For many of these medically complex children, the timing of when the tra- cheostomy is performed and the preoperative discussion regarding ongoing care is significantly challenging. ${ }^{6-8}$ More than $50 \%$ of children with tracheostomy are under the age of $1 \mathrm{y}$ at the time of tracheostomy placement. ${ }^{9}$ Decannulation rates for these children are extremely low, ranging from 28 to $51 \%,{ }^{10-16}$ and in those children who are decannulated, the average time the tracheostomy is present is 2 y. ${ }^{10-16}$ 
In this review, timing of tracheostomy placement, tracheostomy procedure techniques, and optimal decannulation protocols in the pediatric population are discussed, along with a comprehensive review of the literature. The complexity of pediatric tracheostomy patients presents both challenges and opportunities for optimizing their quality of care. Recent quality improvement work and its impact on tracheostomy outcomes are specifically addressed.

\section{Overview of Tracheostomy}

The Italian physician Antonio Musa Brassolva performed the first reported successful tracheostomy in the early 15th century for relief of airway obstruction secondary to enlarged tonsils. ${ }^{17}$ Well-documented studies of tracheostomy, however, did not appear until the early 1900s, when the procedure was standardized by the otolaryngologist Chevalier Jackson (1865-1958). ${ }^{18}$ Since that time, pediatric tracheostomy has become a valuable procedure in children with severe respiratory compromise or upper-airway obstruction. ${ }^{9}$

\section{Indications for Tracheostomy and Patient Characteristics}

Both the indications for tracheostomy and the characteristics of children with tracheostomy have changed significantly over the last 50 years, reflecting the changes that have occurred in the management of critically ill children. ${ }^{16,19-21}$ Before the introduction of widespread vaccination (Haemophilus influenza and Corynebacterium diphtheria), acute viral and bacterial infections, such as croup, diphtheria, and epiglottitis, were the leading causes of airway compromise leading to pediatric tracheostomy. ${ }^{19,22}$ The expectation was for short duration of the tracheostomy with decannulation in most cases.

In the late 1900s, the increased use of endotracheal intubation and respiratory support for premature infants, which revolutionized neonatal care, led to greater survival

Dr Watters is affiliated with the Department of Otolaryngology and Communication Enhancement, Boston Children's Hospital, Boston, Massachusetts.

Dr Watters has disclosed no conflicts of interest.

Dr Watters presented a version of this paper at the 55th RESPIRATORY CARE Journal Conference, "Pediatric Respiratory Care," held June 10-11, 2016, in St Petersburg, Florida.

Correspondence: Karen Watters MB BCh BAO MPH, Department of Otolaryngology and Communication Enhancement, Boston Children's Hospital, 300 Longwood Avenue, LO-367, Boston, MA 02115. E-mail: karen.watters@childrens.harvard.edu.

DOI: $10.4187 /$ respcare. 05366 in premature infants with the need for prolonged respiratory support and associated upper-airway abnormalities. ${ }^{19,23,24}$ Tracheostomy is now frequently performed in children who have upper-airway anomalies (either congenital or more commonly acquired secondary to prolonged intubation) or need prolonged mechanical ventilation due to respiratory failure. ${ }^{3,25}$ There has been an increase in the number of children surviving with complex medical needs for whom tracheostomy and/or home ventilation is now part of their chronic disease management. ${ }^{3,9,26}$ Tracheostomy is also performed more frequently in children with chronic conditions, including neurological impairment, and congenital heart and lung disease. A retrospective analysis of 917 children age $0-18$ y undergoing tracheostomy from 36 children's hospitals from 2002 to 2007, demonstrated that chronic lung disease (56\%), neurological impairment (48\%), and upper-airway anomaly $(47 \%)$ were the most common underlying comorbid conditions. ${ }^{9}$ Of the $>4,800$ pediatric tracheostomies performed in the United States annually, 33\% are reported to be performed on infants. ${ }^{27}$ Of 206 children who underwent an elective tracheostomy from 2012 to $2013,34.0 \%$ were neonates, $54.4 \%$ were born prematurely, $97.6 \%$ were categorized as American Society of Anesthesiologists class 3 or higher, and $75.7 \%$ required nutritional support. ${ }^{28}$

\section{Patient Evaluation}

\section{Timing of Tracheostomy in Children}

Tracheostomy has become a routine clinical intervention in adult critical care, being performed in $10-24 \%$ of ventilated adult patients..$^{29,30}$ The average number of tracheostomies has steadily increased to $>100,000$ annually; approximately 4,000 of these were performed in pediatric patients. ${ }^{31}$ The trend is also for tracheostomy to be carried out even earlier in the patient's ICU stay. ${ }^{32}$ A recent comprehensive review of the Project IMPACT database (109 ICUs) documented that tracheostomy placement in adults occurred at a median of $9 \mathrm{~d}$ (interquartile range 5-14d) after ICU admission. Up to $34 \%$ of adult patients who require mechanical ventilation for $>48 \mathrm{~h}$ eventually receive a tracheostomy for prolonged mechanical ventilation. A survey of adult practice in the United Kingdom reported that the majority of respondents would consider tracheostomy indicated at $<10 \mathrm{~d}$ of mechanical ventilation. ${ }^{30}$ Previously, it was considered reasonable to wait at least $10 \mathrm{~d}$ to be certain that a patient has an ongoing need for mechanical ventilation or assistance with pulmonary toilet before consideration of tracheostomy in adults. However, evidence and debate to date have started looking at a cutoff of $72 \mathrm{~h}$ or less of intubation. ${ }^{33}$ 
Contrary to adult practice, tracheostomy is a much less common procedure in the pediatric ICU, and much less is known about current practice. Although there is consensus that tracheostomy has to be performed in 1 or 2 weeks of ventilation in adult patients, no established criteria currently exist regarding time to tracheostomy for children, and thus each patient is evaluated individually. ${ }^{34,35}$ It is known that pediatric patients tolerate intubation for a longer period than do adults; however, tracheostomy may be helpful for weaning by decreasing the work of breathing. ${ }^{36}$ It may also allow patients with chronic respiratory insufficiency to receive mechanical ventilation at home, thus decreasing the length of hospital and pediatric ICU stays. It is reported that only just over $2 \%$ of pediatric patients will receive a tracheostomy. ${ }^{29}$ Tracheostomy is also usually performed much later in the hospital course, and there is no definite consensus about the length of time a child should remain endotracheally intubated before the placement of a tracheostomy. ${ }^{29,37}$ Some preterm infants are intubated for $>3$ months before tracheostomy is considered. Lewis et $\mathrm{al}^{19}$ estimated that 4,861 tracheostomies were performed in pediatric patients in the United States in 1997 (0.07\% of all pediatric admissions) and found that practice varied considerably by region. A study of pediatric ICUs in the United Kingdom (1,613 tracheostomies total) found a $2 \%$ incidence of tracheostomy, with institutional incidence varying from 0.13 to $5.66 \%$ among institutions. ${ }^{29}$ Prolonged invasive ventilation was the primary indication for tracheostomy in 25 of 29 units, but the definition varied between 14 and $90 \mathrm{~d}$, and most respondents considered timing on an individual basis. Wakeham et $\mathrm{al}^{36}$ studied tracheostomies in children by analyzing 13,232 pediatric ICU admissions in 82 pediatric ICUs who required mechanical ventilation for $\geq 3 \mathrm{~d}$. They found that $6.6 \%$ of these subjects eventually received a tracheostomy ( $48 \%$ of whom were also discharged receiving mechanical ventilatory support), and there was also significant variation in the use and timing of tracheostomy across these units.

In a retrospective analysis of 917 children undergoing tracheostomy from 36 children's hospitals in 2002 with follow-up through 2007, Berry et $\mathrm{al}^{9}$ reported that $48 \%$ of children requiring tracheostomy were $<6$ months of age at the time of tracheostomy placement. Also, many neonates in the study undergoing tracheostomy experienced lengthy pre-tracheostomy intubations and multiple failed extubation trials before tracheostomy placement. In a single institutional report of 95 subjects from 2010 to 2011, Liu et $\mathrm{al}^{4}$ reported that tracheostomy placement occurred at an average of $42.2 \mathrm{~d}$ after admission, with the mean length of in-patient stay being $87.8 \mathrm{~d}$.

A more recent retrospective analysis of 73 North American pediatric ICUs reported that among 115,437 admitted pediatric ICU patients between 2009 and 2011,
$1.37 \%$ (1,583 subjects) received a new tracheostomy during that admission, and $0.6 \%$ (168 subjects) had a tracheostomy already in place. ${ }^{38}$ The majority of children in this study had complex chronic conditions that contributed to their airway compromise or chronic respiratory failure, and most tracheostomy placements were initiated during unplanned pediatric ICU admissions and after acute/acute-on-chronic critical illness. Elective tracheostomy is rare in the pediatric setting. Across the enrolled pediatric ICU sites, the median incidence of initiating tracheostomies was low; however, there was significant variability in the ranges $(0-2.5 \%)$ of incidences. There was also variability among sites regarding the timing of tracheostomy and number of extubation trials before tracheostomy.

In the United States, studies have demonstrated that the time for insertion of a tracheostomy tube is, on average, $14.4 \mathrm{~d}$, although it varies significantly in units from 4.3 to 30.4 d. ${ }^{29,36}$ Holloway et al ${ }^{39}$ analyzed 73 subjects with a median of $22 \mathrm{~d}$ of ventilation before tracheostomy, and results suggested that a longer duration of ventilation before tracheostomy is associated with increased ICU morbidities and stay. Early tracheostomy was recommended, suggesting that it may have significant benefits without adversely affecting mortality. Thus, after 2 weeks of intubation in a child, one should consider tracheostomy evaluation, provided the child is stable on the ventilator.

\section{Preoperative Considerations}

Tracheostomy is being increasingly performed in children with complex chronic conditions. Of a retrospective cohort of 502 children who underwent tracheostomy in $2009,62 \%$ had a complex chronic condition, $43 \%$ had 3 or more chronic conditions, and $29 \%$ had other medical technology (e.g., gastric feeding tubes, ventriculoperitoneal shunts, etc.) in addition to tracheostomy..$^{40}$ In the majority of these children, the tracheostomy may be required for a number of years, if not a lifetime, with an ongoing need for long-term, complex tertiary care and labor-intensive home care, especially in those children requiring chronic ventilatory support. ${ }^{41,42}$ Tracheostomy in children also requires intense support from parents and caregivers, who all need to be appropriately trained in caring for the tracheostomy. Such care needs, dependencies, and impact on families needs to be addressed before placing a tracheostomy in a child.

Determining which children are appropriate candidates for tracheostomies can at times be controversial, especially when the children have profound disabilities or life-limiting conditions. Guidance and counseling for the families of these children with multiple chronic diagnoses on what to expect long-term following tracheostomy continues to remain challenging. ${ }^{40}$ Reported death rates for children, 
especially infants, undergoing tracheostomy are high. Nearly $8 \%$ of children do not survive the hospital stay when the tracheostomy is performed.9,19 Singleinstitutional studies have revealed $9-15 \%$ mortality rates up to $10 \mathrm{y}$ after tracheostomy. ${ }^{43-45}$ However, $<3 \%$ of this mortality is directly attributable to tracheostomy-related adverse events. The majority of deaths are secondary to the child's underlying chronic conditions. ${ }^{19,26}$ Between 15 and $19 \%$ of children experience a tracheostomy-related complication. ${ }^{9}$ A recent study reported that this rate may be as high as $38.8 \%$ in children in the first 2 y after tracheostomy. ${ }^{40}$ Tracheostomy-related adverse events include, among others, tracheostomy-related hemorrhage, tracheoesophageal fistula, tracheal stenosis, and tracheostomy tube obstruction.

\section{Tracheostomy Tube Types}

Before the 1960s, tracheostomy tubes were made from stainless steel or silver. These tubes caused very minimal stomal tissue reaction but did not conform to the airway well and could cause significant irritation and bleeding of the tracheal mucosa. Holinger et $\mathrm{al}^{46}$ helped to alleviate some of these issues by introducing a modification of the Jackson tube, which was shortly followed by the introduction of a more anatomically shaped tracheostomy tube made of polyvinyl chloride (PVC). Nowadays the majority of pediatric tracheostomy tubes are made of PVC (eg, Shiley) or silicone (eg, Bivona), which cause minimal tissue reaction. Metal tubes can still be manufactured on an individual patient basis and can be very helpful in those with severe incalcitrant stomal issues.

\section{Adult Versus Pediatric}

Pediatric tracheostomy tubes differ from adult tubes in a number of ways. Pediatric tracheostomy tubes are single lumen, regardless of manufacture. There is no removable inner cannula. Fenestrated pediatric tracheostomy tubes are not available. Pediatric tubes are manufactured in standard neonatal and pediatric sizes. Generally, children up to approximately $5 \mathrm{~kg}$ use the neonatal size. The standard way to determine the adequate length is by performing a flexible tracheoscopy through the tube to assess the lower tube position in relation to the carina.

\section{Tracheostomy Tube Size}

It is very important that the size of the tracheostomy tubes that is selected is appropriate for both the size of the child's airway and the clinical indication for placement of the tracheostomy tube. Generally, the smallest tube capable of giving adequate air exchange is chosen. A larger- diameter tube may be required for ventilator-dependent patients to prevent significant air leak. An oversized tube may result in tracheal mucosa injury with ulceration and bleeding and subsequent fistulization or tracheal stenosis. A tube that is too long may migrate into the right main bronchus. An age-appropriate tracheostomy tube size can be estimated by using the endotracheal tube (ETT) formula for children $>1 \mathrm{y}$ of age: (age in years/4) + $4 \mathrm{~mm}=$ internal diameter of ETT. This can then be converted to the appropriately sized tracheostomy tube (Table 1).

\section{Cuffed and Uncuffed Tubes}

An uncuffed tracheostomy tube is the preferred tube type in a child except in cases where there is a ventilatory requirement. Previously, only cuffless pediatric tracheostomy tubes were available. There were occasional difficulties with large leaks around the tubes in ventilatordependent children. Over the last decade, cuffed pediatric tracheostomy tubes have been introduced. Bivona cuffed tubes are available in all sizes in both neonatal and pediatric sizes, down to a $2.5-\mathrm{mm}$ neonatal cuffed tube. Shiley cuffed neonatal and pediatric tubes are available from a 3.0-mm size.

The silicone Bivona neonatal and pediatric TTS tracheostomy tubes have a low-volume high-pressure tight to shaft (TTS) cuff that is inflated with sterile water using a minimal leak technique. The TTS cuff, when inflated, seals the trachea for a ventilated patient, and when deflated, the cuff rests tight to the shaft of the tube with the appearance and profile of an uncuffed tube. This allows the tube to be used for weaning patients from a ventilator, without having to change to an uncuffed tube, and also aids in speaking. The TTS cuff is inflated with sterile water because the cuff is made of silicone, which is gas-permeable and would allow diffusion of air through the cuff over time. Water does not diffuse and allows a constant cuff volume to be maintained over time.

Bivona Aire-Cuf neonatal and pediatric tracheostomy tubes are also available but are less commonly used. The Aire-Cuf tracheostomy tube provides a traditional cuff option and is ideal for short-term to medium-term ventilator support. Air, not water, is used to inflate the Aire-Cuf. The Aire-Cuf is also made of silicone, but the durometer of silicone is much thicker; therefore, diffusion of air through the cuff is negligible compared with the TTS. The Shiley cuffed pediatric tracheostomy tubes are inflated with air.

\section{Custom Tracheostomy Tubes}

There has been a greater demand for custom pediatric tubes due to the increased survival of infants and children 
Table 1. Pediatric Tracheostomy Sizes: Cross-Reference of Bivona and Shiley Tube Sizes

\begin{tabular}{|c|c|c|c|c|c|}
\hline Brand and Tube & Size & $\begin{array}{l}\text { ID } \\
(\mathrm{mm})\end{array}$ & $\begin{array}{l}\mathrm{OD} \\
(\mathrm{mm})\end{array}$ & $\begin{array}{l}\text { Length } \\
(\mathrm{mm})\end{array}$ & $\begin{array}{c}\text { MRI } \\
\text { (Yes/No) }\end{array}$ \\
\hline \multicolumn{6}{|l|}{ Bivona } \\
\hline \multirow{4}{*}{$\begin{array}{l}\text { Neonatal cuffless and TTS } \\
\text { cuffed }\end{array}$} & 2.5 & 2.5 & 4.0 & 30 & No \\
\hline & 3.0 & 3.0 & 4.7 & 32 & No \\
\hline & 3.5 & 3.5 & 5.3 & 34 & No \\
\hline & 4.0 & 4.0 & 6.0 & 36 & No \\
\hline \multirow{3}{*}{$\begin{array}{l}\text { Neonatal Flextend TTS } \\
\text { cuffed }\end{array}$} & 3.0 & 3.0 & 4.7 & 32 & No \\
\hline & 3.5 & 3.5 & 5.3 & 34 & No \\
\hline & 4.0 & 4.0 & 6.0 & 36 & No \\
\hline \multirow{7}{*}{$\begin{array}{l}\text { Pediatric cuffless and TTS } \\
\text { cuffed }\end{array}$} & 2.5 & 2.5 & 4.0 & 38 & No \\
\hline & 3.0 & 3.0 & 4.7 & 39 & No \\
\hline & 3.5 & 3.5 & 5.3 & 40 & No \\
\hline & 4.0 & 4.0 & 6.0 & 41 & No \\
\hline & 4.5 & 4.5 & 6.7 & 42 & No \\
\hline & 5.0 & 5.0 & 7.3 & 44 & No \\
\hline & 5.5 & 5.5 & 8.0 & 46 & No \\
\hline \multirow{3}{*}{$\begin{array}{l}\text { Pediatric Flextend cuffless } \\
\text { and TTS cuffed }\end{array}$} & 3.0 & 3.0 & 4.7 & 39 & Yes \\
\hline & 3.5 & 3.5 & 5.3 & 40 & Yes \\
\hline & 4.0 & 4.0 & 6.0 & 41 & Yes \\
\hline \multirow[t]{2}{*}{ Adult cuffless } & 5.0 & 5.0 & 7.4 & 60 & Yes \\
\hline & 6.0 & 6.0 & 8.8 & 70 & Yes \\
\hline \multirow[t]{3}{*}{ Adult TTS cuffed } & 5.0 & 5.0 & 7.3 & 60 & Yes \\
\hline & 6.0 & 6.0 & 8.7 & 70 & Yes \\
\hline & 7.0 & 7.0 & 10.0 & 80 & Yes \\
\hline \multicolumn{6}{|l|}{ Shiley } \\
\hline \multirow[t]{4}{*}{ Neonatal cuffless } & 3.0 & 3.0 & 4.5 & 30 & Yes \\
\hline & 3.5 & 3.5 & 5.2 & 32 & Yes \\
\hline & 4.0 & 4.0 & 5.9 & 34 & Yes \\
\hline & 4.5 & 4.5 & 6.5 & 36 & Yes \\
\hline \multirow[t]{6}{*}{ Pediatric cuffless } & 3.0 & 3.0 & 4.5 & 39 & Yes \\
\hline & 3.5 & 3.5 & 5.2 & 40 & Yes \\
\hline & 4.0 & 4.0 & 5.9 & 41 & Yes \\
\hline & 4.5 & 4.5 & 6.5 & 42 & Yes \\
\hline & 5.0 & 5.0 & 7.1 & 44 & Yes \\
\hline & 5.5 & 5.5 & 7.7 & 46 & Yes \\
\hline \multirow[t]{3}{*}{ Pediatric cuffed } & 4.0 & 4.0 & 5.9 & 41 & Yes \\
\hline & 4.5 & 4.5 & 6.5 & 42 & Yes \\
\hline & 5.0 & 5.0 & 7.1 & 44 & Yes \\
\hline \multirow{2}{*}{$\begin{array}{l}\text { Adult cuffed (LPC) and } \\
\text { cuffless (CFS) }\end{array}$} & 4 & 5.0 & 9.4 & 62 & Yes \\
\hline & 6 & 6.4 & 10.8 & 74 & Yes \\
\hline $\begin{array}{l}\text { ID }=\text { inner diameter } \\
\text { OD }=\text { outer diameter } \\
\text { MRI = magnetic resonance imaging co } \\
\text { TTS }=\text { tight-to-shaft } \\
\text { LPC }=\text { cuffed with inner cannula } \\
\text { CFS }=\text { cuffless with inner cannula }\end{array}$ & npatibilit & & & & \\
\hline
\end{tabular}

with complex upper-airway, tracheoesophageal, and craniofacial anomalies. Custom lengths can now be promptly manufactured based on the individual airway of the patient, which is especially useful in children with severe tracheomalacia, whereby a longer tube may help to stent open the airway.
Manufacturers have a custom template form with a range of tube options to make a tube suitable for the anatomy of the patient. Custom tube options include connector (swivel, fixed), shaft style (standard silicone, Hyperflex wire reinforced silicone), curvature, length (variable horizontal and distal lengths), cuff design (TTS, Fome-Cuf, multiple-cuff configuration), cuff position, and neck flange ( $\mathrm{V}$ and straight).

Bivona FlexTend tracheostomy tubes are now stocked in some institutions because they are used so frequently. FlexTend tubes have a permanent flexible tube extension on the proximal side of the neck flange, which helps to keep connections away from the neck, chin, and stoma and also helps to prevent circuits from getting disconnected. This tube type is commonly used in small infants with short, fat necks.

\section{Tracheostomy Procedures in Pediatric Population}

\section{Differences in Pediatric and Adult Upper Airway: Kids Are Not Small Adults}

When planning the approach for tracheostomy placement in infants and children, it is important to first address the differences in adult and pediatric laryngeal anatomy. Both anatomic and physiologic characteristics of the infant trachea require special surgical techniques and adequate postoperative care. ${ }^{47}$

Anatomy. Infants have shorter and fatter necks than adults. The infant larynx is situated more superior and anterior in the neck at the level of the third or fourth cervical vertebra, and it starts to descend at around $2 \mathrm{y}$ of age. Its size is approximately one third that of the adult larynx. The adult larynx is positioned at the sixth or seventh vertebra. The hyoid frequently overlies the thyroid cartilage notch, making palpation of anatomic landmarks difficult at times. The infant thyrohyoid membrane is also much shorter. The cricoid cartilage is the narrowest part of the airway in a child; in adults, it is the vocal cords. ${ }^{48,49}$

Physiology. The cartilages of the infant larynx are softer and more pliable than in adults, with a tendency to collapse if pressure is placed on them. The mucosa of the supraglottis and subglottis are lax in infants and thus more prone to edema when inflamed or injured.

Indication. It is important to be aware of the indication for placing the tracheostomy in a child. ${ }^{50}$ If a tracheostomy is being placed for upper-airway obstruction secondary to abnormal anatomy, such as subglottic stenosis or complete tracheal rings, entry into the airway may be difficult, with risk of damage to the posterior tracheal wall. 
Table 2. Percutaneous Tracheostomy Studies in Children, 1994-2016

\begin{tabular}{|c|c|c|c|c|}
\hline Author(s) & Year & Subjects & Age & Conclusions \\
\hline Toursarkissian et al ${ }^{56}$ & 1994 & $\begin{array}{l}\text { PDT on } 11 \text { children, } 8 \text { at the bedside; } \\
1 \text { intra-operative and } 1 \text { post- } \\
\text { operative complication }\end{array}$ & $10-20 y$ & $\begin{array}{l}\text { PDT can be safely performed on patients } \\
>10 \text { y old }\end{array}$ \\
\hline Zawadka-Glos et al ${ }^{57}$ & 2004 & $\begin{array}{l}\text { TLT on } 3 \text { children; } 1 \text { tube pulled out } \\
\text { during rotation phase and surgical } \\
\text { tracheostomy performed }\end{array}$ & $5-15 y$ & $\begin{array}{l}\text { Alternative for tracheostomy placement in } \\
\text { older children; not in emergency }\end{array}$ \\
\hline Baek et al ${ }^{58}$ & 2005 & $\begin{array}{l}\text { Compared the pathology of the } \\
\text { tracheal framework after both ODT } \\
(n=6) \text { and COT }(n=6) \text { in a } \\
\text { growing animal model }\end{array}$ & Rabbit model & $\begin{array}{l}\text { ODT successful in small, growing animal } \\
\text { model; more favorable and consistent } \\
\text { healing; considered in children who } \\
\text { require tracheostomy at any age }\end{array}$ \\
\hline Principi et $\mathrm{al}^{37}$ & 2008 & $\begin{array}{l}\text { Percutaneous technique is used in } 3 \\
\text { of } 16 \text { PICUs (19\%) in Canada }\end{array}$ & $>5 \mathrm{y}$ & $\begin{array}{l}\text { Role of PT in children requires further } \\
\text { investigation }\end{array}$ \\
\hline Raju et al ${ }^{59}$ & 2010 & $\begin{array}{l}\text { Open method performed in younger } \\
\text { children with higher injury severity } \\
\text { score }\end{array}$ & Adolescents (14.2 y vs $15.5 \mathrm{y}$ ) & $\begin{array}{l}\text { PT can be safely performed in the injured } \\
\text { older child }\end{array}$ \\
\hline Wood et al ${ }^{29}$ & 2012 & $\begin{array}{l}6 \text { of } 27 \text { PICUs in the UK have } \\
\text { performed PT }\end{array}$ & Selected adolescents only & Dependent on operator experience \\
\hline Gollu et al ${ }^{55}$ & 2016 & $\begin{array}{l}51 \text { children; } 6 \text { cases performed using } \\
\text { flexible bronchoscope; perforation } \\
\text { of esophagus on } 6 \text { th patient, } \\
\text { repaired immediately; next } 45 \\
\text { cases performed using rigid } \\
\text { bronchoscope }\end{array}$ & $\begin{array}{l}\text { Mean age } 38 \pm 54 \text { months } \\
\quad(1 \text { month to } 17 \mathrm{y})\end{array}$ & $\begin{array}{l}\text { PT is a safe and feasible procedure in } \\
\text { children, even in small infants; it is } \\
\text { important that it should be done in an } \\
\text { operating room setting and under rigid } \\
\text { bronchoscopic guidance }\end{array}$ \\
\hline $\begin{array}{l}\mathrm{PDT}=\text { percutaneous dilation } \\
\text { TLT }=\text { translaryngeal tracheo } \\
\text { ODT }=\text { open dilatational trac } \\
\text { COT }=\text { conventional open tra } \\
\text { PICU = pediatric intensive c: } \\
\text { PT }=\text { percutaneous tracheostc }\end{array}$ & $\begin{array}{l}\text { tracheost } \\
\text { omy } \\
\text { ostomy } \\
\text { ceostomy } \\
\text { eunit } \\
\text { yy }\end{array}$ & & & \\
\hline
\end{tabular}

\section{Percutaneous Tracheostomy}

Percutaneous tracheostomy has largely replaced the traditional surgical tracheostomy in adult patients. It is considered a safe and an easy bedside procedure that does not damage tracheal cartilages and, in addition, has better cosmetic results. ${ }^{51-53}$ However, in sharp contrast, the percutaneous tracheostomy technique is rarely used in children, due to concerns about the safety of the procedure and technical limitations, especially in young children and infants. 54,55

Almost 50\% of pediatric tracheostomies are performed in infants $<1$ y of age, ${ }^{9}$ who have extremely small airways, and palpation of anatomical landmarks can be difficult, making it hard to accurately insert the needle for guiding the wire and tracheostomy cannula at the correct region. In addition, providing adequate ventilation through a flexible bronchoscope inserted through a small endotracheal tube, especially in small infants, may not be possible. The pediatric trachea is also more mobile, pliable, and softer, with a tendency to collapse when pressure is exerted with the dilators, thereby increasing the risk of damage to the posterior tracheal wall. ${ }^{53-56}$ Also, the indication for which the tracheostomy is initially required may be a limitation, such as in cases of subglottic stenosis, tracheal stenosis, or tracheomalacia, where percutaneous cannulation of a narrowed tracheal lumen may prove very difficult. ${ }^{55}$ Finally, accidental decannulation in the early postoperative period may be fatal because of the smaller cannulation site and the absence of stay sutures, which are usually present in a surgical tracheostomy to facilitate tracheostomy tube insertion.

Overall experience with percutaneous tracheostomy in children is extremely limited (Table 2). Large published series describing the appropriate technique and equipment and revealing potential risks and benefits of this procedure in children are lacking. ${ }^{55,57,59}$ The largest series of pediatric subjects to date, by Gollu et al, ${ }^{60}$ prospectively reports data of 51 consecutive children who underwent percutaneous tracheostomy. The mean age of the subjects was $38 \pm 54$ months, and the youngest patient was 1 month old. All procedures were performed in the operating room under general anesthesia. The first 6 procedures were performed under flexible bronchoscopic guidance, using hydrophilic-coated pediatric percutaneous nephrostomy dilators, because pe- 
diatric-size percutaneous tracheostomy dilators were not commercially available. There was one major early complication: perforation of the posterior wall of the trachea and the anterior wall of the esophagus, which occurred in one subject (2\%). The subsequent 45 procedures were thus performed under rigid bronchoscopic guidance. The authors concluded that percutaneous tracheostomy is a safe and feasible procedure in children, even in small infants. However, they stressed the importance that all procedures be done in an operating room setting and under rigid bronchoscopic visualization to prevent complications in pediatric patients.

Other reported series include few children under the age of $10 \mathrm{y}$ and are small in number. Toursarkissian et al ${ }^{56}$ reported on 11 children (10-20 y of age; average age was $16 \mathrm{y})$ who had percutaneous tracheostomy performed. There was one intraoperative (premature wire removal) and one postoperative (mild stomal infection) complication in the same patient, both of which were immediately recognized and treated. They concluded that percutaneous tracheostomy can be safely performed in children $>10 \mathrm{y}$ old. Zawadzka-Glos et al ${ }^{57}$ described percutaneous tracheostomy on 3 children (age 5-15 y). In one subject, the tube was pulled out during the rotational phase, and a surgical tracheostomy was performed. They recommended that percutaneous tracheostomy is an alternative in older children but should not be considered in an emergency and in younger children.

Principi et $\mathrm{al}^{37}$ studied the use of the percutaneous technique in pediatric ICUs in Canada in children $>5 \mathrm{y}$ of age. They reported that the technique was used in 3 of 19 (19\%) pediatric ICUs and that the role of percutaneous tracheostomy in children requires further investigation. Similarly, Wood et al ${ }^{29}$ reported that only 6 of 29 pediatric ICUs in the United Kingdom have performed percutaneous tracheostomy in addition to surgical ones and in selected adolescents only, never in young children. They concluded that the success of the procedure was highly dependent on operator experience.

The effect of the type of tracheal incision in the open surgical approach on the subsequent tracheal stenosis rate in children has been a subject of considerable discussion. Percutaneous tracheostomy may offer the theoretical advantage of avoiding incisions into the cartilage rings, with potentially less scarring and narrowing. ${ }^{58}$ The changes in adult practice have been mostly driven by research data, which are largely absent in the pediatric population, making it difficult to make evidence-based recommendations. Longer follow-up and more patients are needed to determine the long-term benefits of percutaneous tracheostomy in children, as well as to determine the lowest age for its safe performance. ${ }^{60}$

\section{Surgical Tracheostomy}

Pediatric tracheostomies are classically performed surgically. ${ }^{60}$ Various operative techniques have been advocated to minimize the risk and complications of the procedure.

Incision Type. The effect of the type of tracheal incision on the subsequent stenosis and tracheomalacia rate in children has been a subject of considerable discussion, with various operative techniques being advocated to minimize the risk and complications. ${ }^{58,61-63}$ There are 3 main concerns that should be reviewed when a tracheostomy incision site is being considered: prevention of accidental decannulation (this is the primary cause of tracheostomyrelated fatality in children); prevention of long-term tracheal stenosis ${ }^{58,64}$; and awareness of the underlying indication for tracheostomy. For example, if the child has subglottic stenosis that will be repaired as a single-stage procedure in the future, it may be beneficial to place the tracheostomy high in the neck. ${ }^{47}$

There is an ongoing debate as to whether a vertical or horizontal tracheal incision, with or without flap, should be made. ${ }^{62-65}$ The basic principle consists of incising as few tracheal rings as possible. Irrespective of the incision used, the tube is likely to inflict some damage on the tracheal cartilage. Studies have reported no difference in results or complications when different incision types are used. MacRae et al ${ }^{66}$ reported a study of 93 children with tracheostomies with various tracheal incisions and showed no difference when comparing the different types of incisions. A midline vertical incision in infants and young children through the second to fourth tracheal cartilages is the most preferred technique. ${ }^{47}$

Procedure. The child is placed supine with the neck extended. A horizontal midline neck incision is made midway between the cricoid cartilage and sternal notch (Fig. $1, \mathrm{~A}$ and B). The incision is deepened through the subcutaneous fat plane to the strap muscles. Care is taken to stay in the midline. The strap muscles are retracted laterally to enter the pretracheal space. Bipolar cautery is used throughout the procedure to ensure that the surgical field is kept dry. If the thyroid isthmus is obscuring the trachea, it is clamped and divided. The anterior surface of the trachea is exposed over 3-4 rings (Fig. 1C).

Two sutures using 3-0 nylon or vicryl are first vertically placed on either side of where the midline tracheostomy incision will be. These act as stay sutures. A midline vertical incision is then made in the anterior tracheal wall between the second and fourth tracheal rings. The surgeon identifies the endotracheal tube in the trachea and, keeping it in direct vision, then instructs the anesthesiologist to withdraw the endotracheal tube cranially to just below the 


\section{Pediatric Tracheostomy}

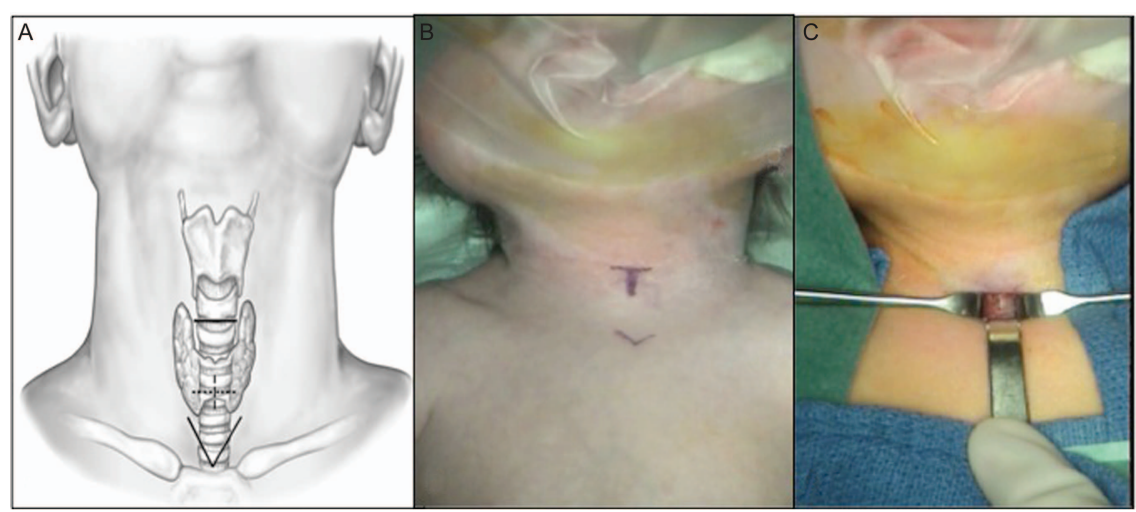

Fig. 1. Open surgical tracheostomy. A: Illustration of incision site. The incision site is placed midway between the cricoid cartilage and the suprasternal notch. B: Skin markings of incision site. C: Midline dissection onto the trachea. Trachea exposed using retractors.

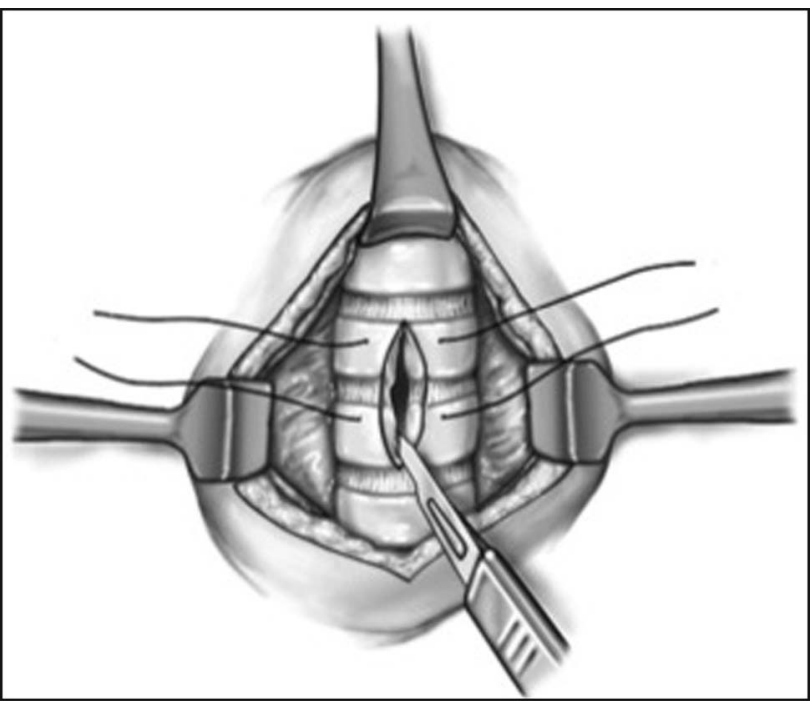

Fig. 2. Illustration of stay sutures placed on either side of a vertical midline tracheostomy incision.

vocal cords. The tracheostomy tube is then placed in the tracheal lumen using the obturator. The obturator is then removed, the tube is connected to the ventilatory circuit, and its correct position is confirmed. The endotracheal tube is not withdrawn from the patient's airway until the ventilatory status of the patient through the tracheostomy tube is satisfactory. The position of the distal tip of the tracheostomy tube, which should rest at least 2-3 rings above the carina, is also checked using a flexible fiberoptic bronchoscope. The tracheostomy is then secured around the neck with Velcro tracheostomy ties. The tracheostomy tube is no longer routinely sutured to the skin, as it is for adults, due to the risk of accidental decannulation occurring in a sutured tube and remaining unnoticed. The shaft of the tube can occasionally slip out of the stoma without the sutures being removed.

Stay Sutures. Stay sutures are typically placed on either side of the vertical incision at the time of a surgical tra-

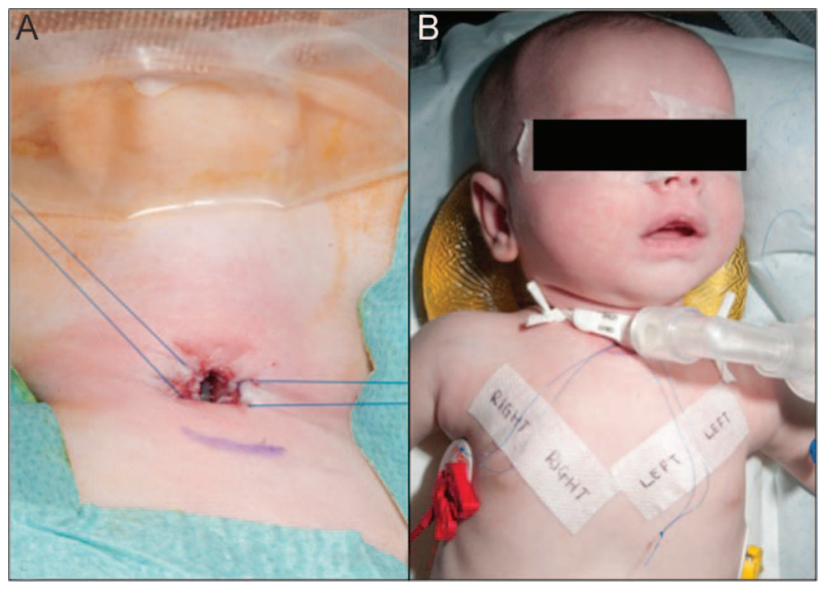

Fig. 3. Open surgical tracheostomy. A: Stay sutures in place on the trachea before insertion of the tracheostomy tube. B: Stay sutures taped onto the chest and marked "right" and "left" at the end of the procedure.

cheostomy in a child (Fig. 2). They are taped on the anterior chest wall and labeled appropriately as "right" and "left" (Fig. 3, A and B). Gentle upward retraction of the stay sutures allows for rapid identification of the newly created tracheostoma in the event of an accidental decannulation, allowing fast replacement of the tube. The sutures are typically removed at the time of the first postoperative tracheostomy tube change. The benefit of placing stay sutures has been debated frequently. Ruggiero et al ${ }^{67}$ reported on a survey conducted on 168 members of the American Society of Pediatric Otorhinolaryngology, $94 \%$ of whom reported that they use stay sutures routinely.

Stoma Maturation. The standard pediatric tracheostomy is a vertical tracheal incision with stay sutures. In addition, there are numerous reports on the benefits and the methods of maturing an infant's tracheostomy stoma to prevent accidental decannulation and formation of granulation tissue. ${ }^{68-70}$ Park et $\mathrm{al}^{71}$ reported a series of 149 pediatric 
tracheostomy subjects, where the stoma was mature in 88 $(59.1 \%)$. In those with a matured stoma, there was a decrease in the morbidity of early accidental decannulation. However, there is a generalized aversion to resecting part of a child's anterior tracheal wall, and most stomaplasty methods involve suturing the skin around the edges of the tracheal opening. In general, these methods are usually only performed in patients where the tracheostomy is expected to be long-term or there is a concern for accidental decannulation. ${ }^{72}$ These include the following. (1) A circular shield of anterior tracheal wall cartilage is removed to create a permanent fenestration in the trachea. (2) The Bjork flap, an inferiorly based anterior tracheal wall flap, which transects a single tracheal ring only, is sutured to the inferior edge of the horizontal tracheostomy skin incision. ${ }^{73}$ The remainder of the skin is then sutured around the tracheal opening. (3) The Eliachar flap, which uses an omega-shaped skin incision and a superiorly based tracheal flap, is created. ${ }^{74} \mathrm{~A}$ circumferential mucocutaneous suture line is created. (4) The starplasty technique, described by Koltai, ${ }^{70}$ entails creating a mature tracheo-cutaneous track through a 3-dimensional Z-plasty technique. The procedure has been shown to be superior to other techniques in reducing the incidence of major complications, including death from accidental decannulation, as well as the incidence of tracheal stenosis after tracheostomy. However, because of the nature and intent of the procedure, nearly $100 \%$ of children will have a persistent tracheocutaneous fistula after decannulation that will require secondary reconstruction. ${ }^{75}$

\section{Physiological Consequences of Tracheostomy}

A tracheostomy tube bypasses the natural mechanisms of filtration, ciliary clearance, warming, and humidification of the air that are usually provided by the nose and oral cavity. Thus, a child with a tracheostomy may experience increased cough, pulmonary infections, and drying of pulmonary secretions. To prevent irritation of the airways, due to dry air, dust, or harmful substances contained in the air, a filter is required. ${ }^{76}$ Humidification and frequent suctioning are essential to reduce the risk of crusting, mucus plugs, and tube blockage.

\section{Humidification}

There are a number of devices available that can assist in humidification. Most bedside ventilators have built-in humidifiers. Sterile saline drops can be instilled into the tracheostomy tube if secretions become thick and difficult to suction. A saline nebulizer treatment may also be helpful to loosen secretions.

Heat-and-moisture exchangers (HMEs) are filter devices for heat and moisture exchange. They are placed on the hub of the tracheostomy tube and are frequently referred to as Swedish noses. Other names include thermal humidifying filters, artificial noses, and Thermovent $T$. These devices house a filter for heat and moisture exchange. During exhalation, heat and moisture are deposited into the filter; during inhalation, the heat and moisture are returned to the lungs. Regular use of HME filter cassettes may help to keep secretions thin and alleviate increased production of mucous and coughing, which is frequently experienced by patients with tracheostomy. HMEs may also help to improve the quality of speech. HMEs may require an increase in work of breathing, which may not be tolerated by some patients. Patients should be closely monitored for dyspnea, fatigue, and desaturation when they are initially trialed with an HME device. Patients with large amounts of secretions may not be suitable for an HME because it may be more difficult to clear them with an HME in place.

A trach collar is a tracheostomy mist collar mask that is worn to provide humidification, especially when mucus is thick or blood-tinged or the child will not tolerate an HME device. Aerosol tubing is connected to the collar mask, with the other end of tubing attaching to a nebulizer bottle and air compressor. Oxygen can also be delivered via the tracheostomy mist collar if needed.

Heated mist may be provided via an electric heating rod that fits into the nebulizer bottle. It is very important to note that more moisture will accumulate in the aerosol tubing with heated mist and must be removed frequently to prevent blockage of the tube and/or accidental aspiration. Excess moisture must be emptied routinely by disconnecting the tubing at the tracheostomy end. The air compressor and tubing must also be kept lower than the patient to prevent aspiration from moisture in the tubing.

\section{Speaking Valves}

Normal speech and language development require vocal exploration and social interaction, both of which are limited when a tracheostomy tube is in place, especially in an infant. ${ }^{77}$ The Passy-Muir valve is a one-way speaking valve that permits inspiration through the tracheostomy stoma, and expiratory flow occurs over the vocal folds promoting phonation. Adults with tracheostomies routinely demonstrate the ability to speak using speaking valves without respiratory compromise. Although there is extensive research to support the use of speaking valves in the adult population, the use of speaking valves in infants and pediatric patients is frequently more challenging, and the literature is scant. ${ }^{78}$ The bias-closed diaphragm design of a speaking valve reestablishes the normal physiology of a closed pulmonary airway system. Its advantages in children include allowing spontaneous voice and expression and improvement in swallowing skills, and it may also be 
helpful in the decannulation of patients. ${ }^{79-81}$ Reports advocate for the early use of speaking valves in children with a tracheostomy tube to facilitate improved developmental outcomes for infants born prematurely, as well as outcomes for full-term infants at risk for delays due to underlying medical conditions.

There are no guidelines regarding the age at which a speaking valve can initially be trialed in infants and how long trialing periods should be. However, there are reports of safe use of speaking valves in infants as young as $13 \mathrm{~d}$ of age in a monitored setting using appropriate guidelines. Before trialing a prolonged mechanical ventilation in a child, it is helpful to perform manometry testing to assess transtracheal pressure. If the pressure is $<20 \mathrm{~cm} \mathrm{H}_{2} \mathrm{O}$, it is more likely that the child will tolerate the valve. If medically acceptable, downsizing the tracheostomy to a smaller size may also help with toleration of the speaking valve.

To consider a speaking valve trial, the child should be awake and responsive, medically stable, tolerate cuff deflation, have a patent upper airway, and be able to manage oral and tracheal secretions. A speaking valve should initially be trialed in a monitored setting, either in-patient or out-patient. The specified time periods of trialing are then recommended based on the patient's response to the valve (ie, tolerance to the change in breathing pattern, fatigue level, and behavioral disposition). Clinical judgment plays a strong role in advancing the speaking valve trial lengths. The child may initially tolerate it for $10 \mathrm{~min}$, and parents are then given instructions to very slowly increase wearing time over the course of 2 weeks of more. Caregivers are educated about speaking valves and must display appropriate knowledge. They are given very strict instructions to remove the valve immediately if the child is in any distress, to only use the speaking valve when the child is closely supervised, and, most importantly, to only use it when the child is awake and never let the child sleep or nap with the speaking valve in place.

Inability to tolerate a speaking valve may be secondary to minimal leakage around the tracheostomy tube or a restricted suprastomal airway. Contraindications to speaking valve use may include severe upper-airway obstruction, bilateral vocal cord paralysis, severe neurological impairment, and an inflated cuffed tracheostomy tube. Speaking valves are usually trialed on children who are on a tracheostomy collar. They can, however, also be trialed on children with a ventilatory requirement, ideally with a PEEP $<12 \mathrm{~cm} \mathrm{H}_{2} \mathrm{O}$ and $\mathrm{F}_{\mathrm{IO}_{2}}<0.6$.

\section{Complications of Tracheostomy in Children}

Complications of tracheostomy are well reported, occurring in $15 \%$ of adult patients. ${ }^{15}$ In an attempt to gather information on the incidence and types of severe or cata-
Table 3. Complications of Pediatric Tracheostomy: Early and Delayed Complications

\begin{tabular}{lc}
\hline \hline \multicolumn{1}{c}{ Early Complications } & Delayed Complications \\
\hline Air leak & Airway obstruction \\
Pneumothorax & Mucus plugging \\
Subcutaneous emphysema & Accidental decannulation \\
Pneumomediastinum & Stomal problems \\
Hemorrhage & Granulation tissue \\
Thyroid gland & Tracheocutaneous fistula \\
Aberrant vessels & Tracheal lesions \\
Innominate artery & Granuloma: suprastomal/distal \\
Injury to surrounding structures & Suprastomal collapse \\
Cricoid cartilage & Subglottic stenosis \\
Esophagus & Hemorrhage \\
Recurrent laryngeal nerve & Stomal \\
Pulmonary edema & Tracheal mucosa \\
Respiratory arrest & Tracheo innominate fistula (rare) \\
Injury caused by tube placement & Tracheoesophageal fistula (rare) \\
Tracheal tear/fistula & Swallowing problems \\
Main bronchus cannulation & \\
Airway obstruction & \\
Mucus plugging & \\
Accidental decannulation & \\
\hline
\end{tabular}

strophic events following tracheostomy in both adults and children, Das et al ${ }^{15}$ surveyed members of the American Academy of Otolaryngology-Head and Neck Surgery. Four hundred seventy-eight respondents experienced approximately one catastrophic event every $10 \mathrm{y}$ and one event resulting in death or permanent disability every $20 \mathrm{y}$. More than $90 \%$ of events were reported as occurring $>1$ week after surgery. However, less is known specifically about complications in children following tracheostomy. Between 15 and $19 \%$ of children experience a tracheostomy-related complication. ${ }^{9,40}$ Adverse events following tracheostomy placement in children range from mild to life-threatening. Numerous studies have demonstrated an increased mortality rate due to tracheostomy complications in emergency situations, severely ill patients, and especially in children. In children, the most common tracheostomyrelated cause of death has been reported to be tube obstruction, followed by tube misplacement and accidental decannulation.

Adverse related tracheostomy events can be divided into those occurring "early" (including the perioperative and immediate postoperative period) and "delayed" (Table 3). It is important that adverse events be quickly recognized and addressed to prevent devastating consequences.

\section{Early Complications}

Air Leak. Pneumothorax, pneumomediastinum, or subcutaneous emphysema has been reported in up to 3-9\% of 
tracheostomies. These complications are most often caused by technical errors during surgery. Despite all precautions to prevent these complications, they still may inadvertently occur. A chest radiograph should be routinely performed when the child returns to the ICU following tracheostomy to check the status of the chest.

Pneumomediastinum. Pneumomediastinum is caused by air dissection between the deep and superficial cervical fascia and then into the mediastinum. Minimizing pretracheal and paratracheal dissection may help to prevent this. Management is expectant.

Pneumothorax. Pneumothorax may be secondary to violation of the pleura, especially where it approaches the trachea low in the neck. A chest drain may be necessary, depending on the size of the pneumothorax.

Subcutaneous Emphysema. Subcutaneous emphysema may result from closing the wound too tightly and air leaking around the tracheal stoma becoming trapped in the subcutaneous tissues. Excessive positive pressure may also contribute to the development of subcutaneous emphysema. Management is expectant.

Hemorrhage. Perioperative hemorrhage may be prevented by meticulous attention to hemostasis throughout the procedure. Bleeding often stops spontaneously but can occasionally persist, and it is important to address it with cautery before the tracheostomy tube is placed. Most bleeding is capillary ooze, often from the thyroid gland and inferior thyroid veins, which lie anterior to the trachea and must be tied if they cannot be displaced laterally. The thyroid isthmus must be ligated if encountered to obtain hemostasis. More significant hemorrhage may be occasionally encountered due to the presence of aberrant vessels or vascular anomalies. The aortic arch may ride high and reach the manubrium, and the innominate vein has been reported to overlap the trachea in the neck. The common carotid artery in a neonate may also appear deceptively like the trachea. Coagulation abnormalities should be ruled out in any child undergoing tracheostomy, especially those with chronic liver disease and thrombocytopenia secondary to sepsis, and abnormalities should be corrected before surgery if possible.

Injury to Surrounding Structures. The cricoid cartilage and tracheal landmarks need to be clearly identified before making an incision in the trachea, to prevent inadvertent incision into the cricoid cartilage, which could result in subglottic stenosis. ${ }^{82}$ Injury to both the esophagus and recurrent laryngeal nerves has also been reported and can be prevented by careful surgical technique. ${ }^{83}$ Esophageal injury is also more likely to occur if there is a na- sogastric tube in the esophagus, with the esophagus being accidentally mistaken for the trachea.

Pulmonary Edema. Pulmonary edema has been reported after the sudden relief of upper-airway obstruction when a tracheostomy is placed. The exaggeration of the transmural pulmonary vascular hydrostatic pressure gradient can result in partial obstruction of the extrathoracic trachea. Treatment is with positive-pressure ventilation.

Respiratory Arrest. Respiratory arrest during tracheostomy has been reported secondary to rapid washout of retained carbon dioxide, resulting in cardiac arrhythmias, hypotension, and loss of ventilatory drive. ${ }^{82}$

Injury Caused by Tube Placement. A false passage may be easily created upon initial insertion of the tracheostomy tube, especially if the incision in the trachea is too small or the tube is aggressively pushed against resistance. Posterior tracheal lacerations may be caused by a similar method. If the tracheostomy tube is the incorrect size and is too large, it may cannulate a main bronchus. It is important to always assess the position of the tube in relation to the carina with a flexible tracheoscopy immediately after it is placed.

\section{Airway Obstruction}

Accidental Decannulation. Accidental decannulation can occur in the immediate postoperative period, and the consequences may be tragic. It can commonly occur as the patient is being moved from bed to bed to travel to the ICU. The presence of stay sutures, especially in a very small infant, will help with replacing the tube through the fresh stoma. However, even if stay sutures are present, it can be exceedingly difficult to replace the tube, and there is a high risk of creating a false tract. In this situation, a stable airway should be obtained by endotracheal intubation if possible. Decannulation can be prevented by correct tracheostomy tube selection and placement, ensuring that the tube is adequately secured, and by stable patient positioning.

Mucus Plugging. Mucus plugging can be prevented by ensuring adequate humidification and meticulous tracheostomy care, with routine suctioning. Constant supervision of a child with a tracheostomy tube is required to prevent plugging. Before discharge, at least 2 caregivers should be identified and trained proficiently in tracheostomy care, including replacing the tube in an accidental decannulation. It is important to stress that the tracheostomy ties should be adequately secured with no more than one fingerbreadth able to pass underneath them. Calm and controlled replacement of the tube is essential. Hurried inser- 


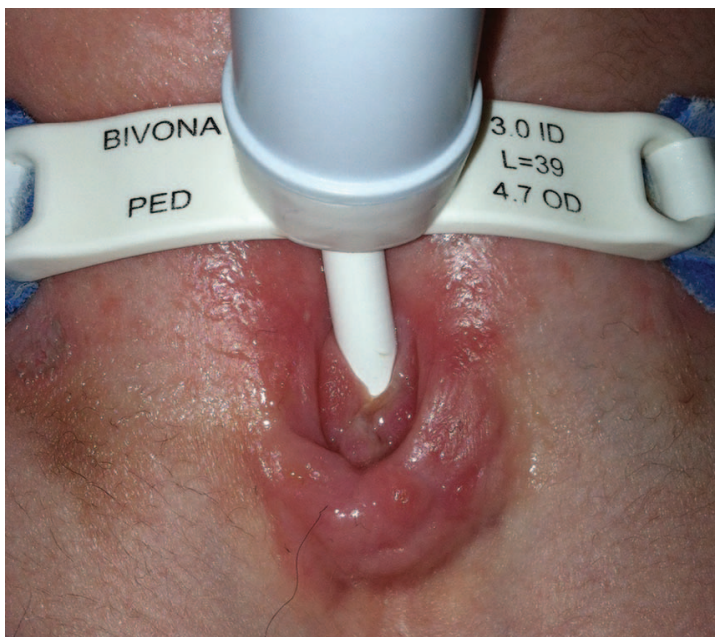

Fig. 4. Peristomal granulation tissue in a 5-y-old child with chronic tracheostomy dependence.

tion of the tube may cause the development of a false passage with subsequent airway obstruction.

\section{Delayed Complications}

Mucus Plugging. Crusts and mucous plugs may obstruct the tracheostomy tube and cause respiratory distress. This can be prevented by proper humidification and meticulous tracheostomy care with regular tube changes. Although tracheal secretions tend to decrease with time as the airway adapts to the presence of the tube, mucus plugging and decannulation remain a hazard as long as the tracheostomy remains in situ. During respiratory tract infections, suctioning and tube changes may be required more frequently.

Accidental Decannulation. Accidental decannulation may occur if the tube is not secured correctly with ties or there is excessive torque from ventilator tube in those who are ventilator-dependent. Some children may also frequently pull out their tracheostomy tube for behavioral reasons. It is thus important that every carer for a child with tracheostomy is appropriately trained and proficient in tube changes.

\section{Stomal Problems}

Granulation Tissue. Peristomal granulation tissue may develop secondary to the friction and movement of the tracheostomy tube or chronic inflammation. (Fig. 4) It usually responds to local wound care and more frequent tracheostomy tube and dressing changes. Treatment is topical antibiotic, and steroid ointment is sometimes required. Occasionally, silver nitrate cautery is required for control of exuberant granulation tissue. There are now also a num- ber of silver-coated wound dressings on the market (Mepilex AG, Mölnlycke Health Care, Gothenburg, Sweden), which are very effective in treating recurrent granulation tissue. Increasing the frequency of tracheostomy tube changes from once a month to bimonthly or even weekly can also help with stomal wound care, because the tube may harbor bacteria in the form of biofilms. Scar tissue may also from around the stoma and may make tube changes difficult. In some cases the stoma may need to be surgically revised.

Tracheocutaneous Fistula. The incidence of a persistent tracheocutaneous fistula is very common in chronically tracheostomy-dependent children and has been reported as high as $42 \%$. Some do not consider it a complication; thus, it may be underrecorded as a complication in some series. The fistula is formed by the apposition of the skin to the tracheal mucosa. Its incidence is significantly increased when the stoma is matured, occurring in $80 \%$ of cases. If the fistula persists for longer than 6 months following decannulation, the tract can be surgically excised down to the trachea and oversewn at the level of the trachea with primary closure of the skin. It is important to place a drain during closure to prevent development of subcutaneous emphysema and pneumomediastinum, which can be fatal. In some institutions, the wound is left open and allowed to close by secondary intention to prevent this complication.

\section{Tracheal Lesions}

Suprastomal Granuloma. Suprastomal granulomas are vey common in children with longstanding tracheostomy. Diagnosis is by direct endoscopic assessment, and depending on the extent of the granuloma, treatment may be necessary (Fig. 5). It is recommended that suprastomal granulomas be removed only immediately before decannulation unless they are significantly obstructing the suprastomal airway, bleeding, or preventing passage of air for speech. An obstructing suprastomal granuloma places the child at risk if there is an accidental decannulation. In the majority of cases, the granuloma can be removed endoscopically using an optical forceps or powered instrument (microdebrider) or a sphenoid punch through the stoma. Rarely, a huge obstructing granuloma may require an open approach with stomal revision to deliver and remove it. Suprastomal collapse that is preventing decannulation may require an open tracheoplasty with cartilage graft placement and endotracheal stenting.

Suprastomal Collapse. The incidence of suprastomal collapse may increase inversely with the age of the child at the time of tracheostomy placement. Pressure on the first and second tracheal rings can cause local chondritis 


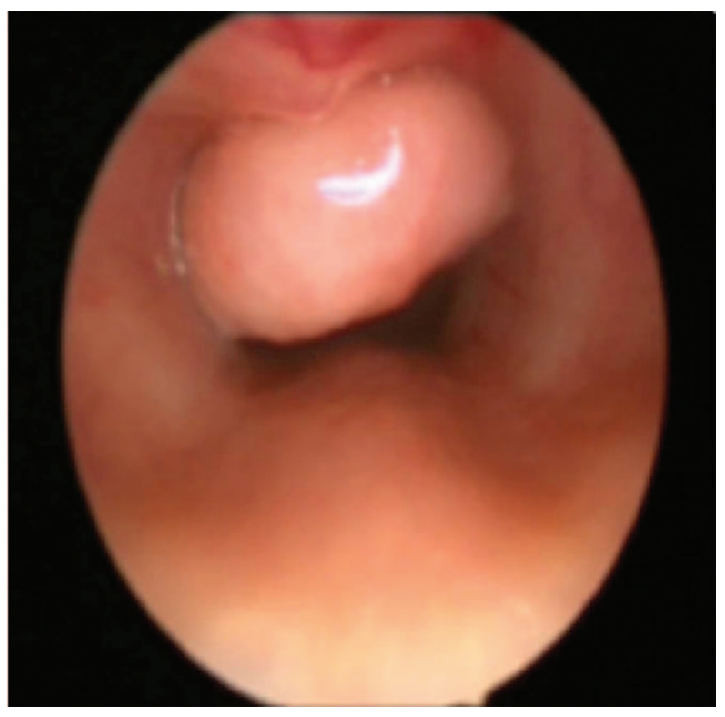

Fig. 5. Large suprastomal granuloma. It was necessary to remove this granuloma before decannulation in this child.

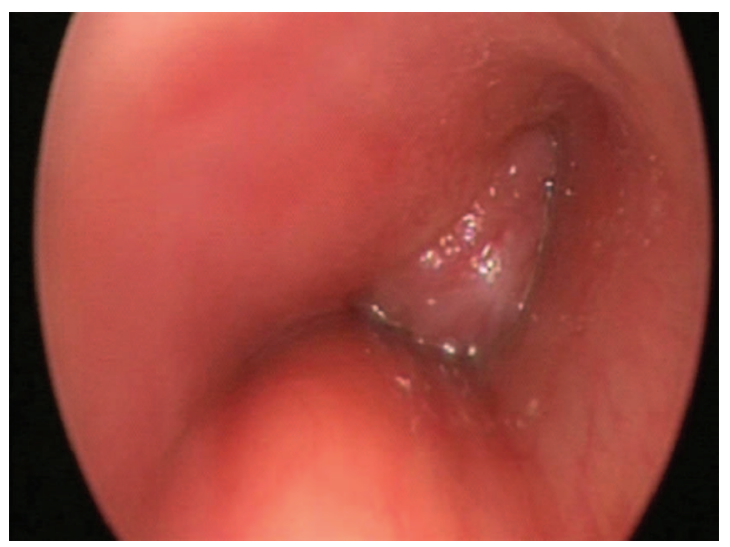

Fig. 6. Anterior suprastomal collapse with suprastomal granuloma completely obstructing the suprastomal airway. This child required open surgical tracheoplasty to facilitate decannulation.

and weakening of the tracheal cartilage, causing tracheomalacia in the suprastomal region (Fig. 6). If the collapse causes significant suprastomal obstruction, it may prevent decannulation. A tracheoplasty, which may include placement of a cartilage graft or segmental resection, may be required. Prevention of this complication is not always possible. Meticulous initial placement of the tube in the correct level of the trachea may help protect against it. Removal of tracheal cartilage at the time of tracheostomy will increase the risk of suprastomal anterior wall collapse.

Subglottic Stenosis. Subglottic stenosis can be the result of placement of the tracheostomy tube too high in the airway. ${ }^{50}$ Other factors that contribute may include trauma from prolonged endotracheal intubation and low-grade in- flammation, often seen in uncontrolled reflux. Meticulous tracheostomy care and placement can help to prevent it. Following decannulation, children can commonly have an "A-frame" deformity or localized malacia at the subglottic/upper tracheal level. Symptoms secondary to this may only become apparent after decannulation. Adequate endoscopic assessment before decannulation should anticipate this complication, and it can be corrected surgically by a tracheoplasty with a cartilage graft or a segmental tracheal resection.

Hemorrhage. In all cases of bleeding from the tracheostomy tube, a bedside flexible tracheobronchoscopy should be performed in an attempt to identify the source of the bleeding. If the source of bleeding cannot be identified and bleeding persists, a formal airway evaluation (direct laryngobronchoscopy) should be performed under general anesthesia.

Stomal. Bleeding may be caused by peristomal granulation tissue and inflammation. Treatment is with topical antibiotics and silver nitrate cautery.

Tracheal Mucosa. Episodes of intermittent hemorrhage from the tracheostomy tube may be caused by tracheitis or granulation tissue within the tracheal lumen. Tracheitis is caused by a bacterial infection of the tracheal mucosa. Frequent suctioning may be required due to increased secretions, which also can irritate tracheal mucosa and cause bleeding. Treatment is with systemic antibiotics and increased humidification. It is also important that an appropriately-sized suction catheter to the correct length is used to ensure that excessive tracheal trauma is not being caused with suctioning. Intra-tracheal granulation tissue, often at the tip of the tracheostomy cannula, may cause hemoptysis or tube obstruction. This tissue can be removed with optical forceps or potassium titanyl phosphate or $\mathrm{CO}_{2}$ laser and injection with intralesional steroids to help prevent recurrence. Nowadays, granulation tissue is being treated with topical antibiotic steroid drops (Ciprodex, Alcon Laboratories, Fort Worth, Texas), which are available on an individual basis and have shown good success.

Tracheoinnominate Artery Fistula. Sudden massive tracheal hemorrhage may be secondary to a tracheoinnominate artery fistula. This is more likely to occur in children with chronic tracheostomy dependence and is caused by the tip of the tracheostomy tube eroding through the anterior tracheal wall into the innominate artery. Such hemorrhage may be heralded by smaller less significant episodes of bleeding. A computed tomography-arteriogram should be performed to assess the position of the innominate artery in relation to the tracheostomy tube. Pulsations may also be seen in the region of the innominate artery at 
the tip of the tracheostomy tube on tracheoscopy. Any patient suspected of impending innominate artery rupture should receive urgent exploration by a cardio-thoracic surgeon. Massive bleeding suggestive of a tracheoinnominate artery fistula should be initially tamponaded with digital pressure followed by placement of a cuffed endotracheal tube. The fistula can be surgically repaired if the patient survives the bleeding. Although tracheoinnominate artery fistula is extremely rare in patients with tracheostomy, its mortality rate approaches $100 \%$.

Tracheoesophageal Fistula. Pressure from the distal end of the tracheostomy tube on the posterior tracheal wall may cause erosion of the posterior trachea and anterior esophageal wall with formation of a tracheoesophageal fistula. A chronically overinflated tracheostomy tube cuff can also cause similar erosion. This complication is very rare but is seen more commonly nowadays in immunocompromised children with poor healing who are tracheostomy-dependent. Children with tracheal anomalies and severe scoliosis or kyphosis are also at greater risk. The presence of a longstanding nasogastric tube may also cause compression and necrosis of the tissue between the nasogastric tube and the tracheostomy tube.

Swallowing Problems. A tracheostomy may interfere with swallowing by anchoring the trachea to the strap muscles and tethering the suprahyoid musculature. An inflated tracheostomy cuff may also cause increased pressure in the esophagus and hypopharynx. It is also reported that the normal laryngeal reflex that prevents aspiration may be lost in patients with chronic tracheostomy. In children who are fed orally before tracheostomy, it is important to have them evaluated by the feeding team and be encouraged to feed orally if it is safe to do so and their medical conditions allow. It should be noted that the presence of a tracheostomy tube is not a contra-indication to oral feeding.

\section{Decannulation in Infants and Children}

\section{Evidence to Date}

Mortality attributed to pediatric tracheostomy ranges from 0.5 to $5 \%, 84$ with European and American reviews citing mortality rates of 3.2 and $3.6 \%$, respectively. ${ }^{16,85}$ Decannulation as soon as the child's underlying conditions permit is therefore advisable and is the ultimate goal shared by patient, family, and provider alike. Acute decannulation failures can be catastrophic, and this risk should be minimized. Children with tracheostomy tubes may become candidates for decannulation through resolution of the underlying airway abnormality, natural expansion of the crosssectional area of the airway with growth, or surgical pro- cedures designed to open narrowed airways. It is paramount that decannulation be undertaken only after being determined safe and appropriate. Decannulation failure rates vary from 6.5 to $21.4 \% .10,15,86$

To date, the literature is devoid of well-established guidelines for determining the readiness for decannulation. The lack of consensus for an optimal decannulation protocol can, in part, be attributed to the paucity of prospective studies focusing on decannulation or studies comparing various decannulation methods. Studies have attempted to define clinical predictors of successful decannulation. ${ }^{15,86-91}$ Although agreement does exist among authors that before decannulation certain investigations need to be performed and criteria obtained, different proposals have been put forth. The literature discusses a myriad of protocols that use varying combinations of in-patient/out-patient resources, specialized tests, and procedures. This has lead to substantial variability in the duration of hospitalization for patients undergoing decannulation and represents an opportunity for improved use of resources. An ideal protocol should present an efficient utilization of resources while not sacrificing patient safety.

Publications on pediatric decannulation over the last $20 \mathrm{y}$ are listed in Table 4. Decannulation protocols vary widely in these reports, with success rates ranging from 67 to $94 \%$.

\section{American Academy of Otolaryngology and Head and Neck Surgery Consensus 2013}

A clinical consensus statement on pediatric tracheostomy management that commented on decannulation was published by Mitchell et al ${ }^{86}$ under the guidance of the American Academy of Otolaryngology and Head and Neck Surgery. The recommendations were constructed from expert opinions and state that specific criteria should be met before attempting decannulation in children, provided there is resolution or improvement of the original indication for tracheostomy.

First, no ventilatory support should be required for a period of 3 months before decannulation, which could vary from 2 to 4 months, depending on the time of the year. Second, there should be no aspiration events, such that a tracheostomy would still be needed for suctioning to maintain pulmonary toilet. A flexible laryngoscopy should be performed to document a patent airway with at least one mobile vocal cord. Removal of any obstructing suprastomal granulation should be performed at the time of bronchoscopy before a decannulation attempt. A daytime tracheostomy tube capping trial is recommended for those children of at least $2 \mathrm{y}$ of age leading up to decannulation. If the child tolerates capping, options before decannulation to assess for readiness may include a capped sleep study, a capped exercise test, or a nighttime capping trial while hospitalized and being observed. In younger or smaller 
Table 4. Pediatric Tracheostomy Decannulation Studies: 1996-2016

\begin{tabular}{|c|c|c|c|c|}
\hline Year & Author & $N$ & Primary Recommendation & Success $(\%)$ \\
\hline 2016 & Cristea et al $^{92}$ & 189 & DLB + decannulation in sleep laboratory receiving PSG & 79.5 \\
\hline 2016 & Wirtz et al ${ }^{90}$ & 35 & Decannulation at airway endoscopy if suitable; conservative approach to resource utilization & 94.2 \\
\hline 2015 & Robison et $\mathrm{al}^{87}$ & 28 & Role of PSG as useful adjunct; AHI $<2.75$ predictor of successful decannulation & 71.4 \\
\hline 2015 & Gurbani et al ${ }^{93}$ & 59 & $\begin{array}{l}\mathrm{AHI} \text { and end-tidal } \mathrm{CO}_{2} \text { good predictors of decannulation; using both favorable MLB and PSG } \\
\text { to predict decannulation }\end{array}$ & NA \\
\hline 2015 & Prickett et al $^{88}$ & 46 & In-patient observation for a $24-\mathrm{h}$ asymptomatic interval after decannulation is sufficient & 91 \\
\hline 2013 & Mitchell et al ${ }^{86}$ & & Recommendations regarding suitability for decannulation and capping $(>2 \mathrm{y})$ & NA \\
\hline 2004 & Kubba et $\mathrm{a}^{94}$ & 4 & Modified protocol in $<13$ months; downsize to size 2 tube in small infants & NA \\
\hline 1999 & Mukherjee et al ${ }^{95}$ & 31 & PSG is a useful adjunct to evaluating readiness for decannulation in children & 67.7 \\
\hline 1997 & Waddell et al ${ }^{96}$ & 84 & Determine minimum safe duration of in-patient stay & 79 (first attempt) \\
\hline 1997 & Merritt et al ${ }^{97}$ & 10 & Decannulation over $24-48 \mathrm{~h}$ after removal of suprastomal granulation; capped fenestrated tube & 90 \\
\hline 1996 & Tunkel et al ${ }^{91}$ & 16 & PSG useful in evaluating readiness for decannulation; AHI $<1.7$ & 81.3 \\
\hline \multicolumn{5}{|c|}{$\begin{array}{l}\text { DLB }=\text { direct laryngobronchoscopy } \\
\text { PSG = polysomnography } \\
\text { AHI = apnea-hypopnea index } \\
\text { MLB = microlaryngoscopy and bronchoscopy } \\
\text { NA = not applicable }\end{array}$} \\
\hline
\end{tabular}

children, the small size of the trachea in relation to the tracheostomy tube may preclude capping, and the decannulation protocol should be tailored to the individual patient. These recommendations serve as a guideline based on the existing evidence, and it was stated in the report that there remains room for further discussion and research on the subject.

\section{Readiness for Decannulation}

Decannulation readiness is approached in several ways and is tailored to the individual patient. The timing and process of decannulation are dependent on several factors. Clinical readiness for decannulation involves cessation of the need for mechanical ventilation for at least 3-6 months and resolution of the original indication for tracheostomy. A supplemental oxygen requirement should not preclude a decannulation trial as long as the child can tolerate oxygen administration via nasal cannula. Comorbidities affecting the need for tracheostomy, including cardiac, pulmonary, or neurologic conditions, should have improved or resolved. A likelihood of needing elective surgery in the future (eg, spinal surgery, oromaxillofacial surgery) that may affect the airway caliber in a child would support the maintenance of the tracheostomy.

Certain assessments of airway form and function are important in all patients before decannulation. Whereas microlaryngoscopy and bronchoscopy evaluate airway patency at all levels, polysomnography (PSG) assesses sleep-related upper-airway physiology. ${ }^{87}$ Numerous decannulation protocols in the literature vary widely in methods. ${ }^{90,92}$

\section{Ideal Decannulation Protocol}

The ideal decannulation protocol should contain some of the following: tracheostomy size reduction and clinical observation; complete airway evaluation (flexible laryngoscopy and direct laryngoscopy bronchoscopy); capping trial at home during the day; capped PSG; and admission for decannulation and post-decannulation observation for 24-48 h; noninvasive ventilation (NIV).

Downsize Tracheostomy Tube Size and Clinical Observation. The child's tracheostomy tube is initially downsized to the smallest tolerated uncuffed tube according to the patient's age and size. In infants, this tube is a size 3.0 uncuffed tube. Although a size 2.5 tracheostomy tube is available, its lumen is so small that it is rarely used outside of a hospital setting due to the concern for mucous plugging of the tube and difficulty suctioning, a potentially fatal complication. ${ }^{94,96}$

Airway Evaluation. The importance of a formal airway evaluation, direct laryngobronchoscopy, before decannulation under general anesthesia is not disputed. A flexible laryngoscopy should be initially performed with the child awake to assess vocal cord movement and supraglottic collapse. Tonsils and adenoids should be evaluated, and if there is evidence of obstructive adenotonsillar hypertrophy, surgical treatment in the form of an adenotonsillectomy/tonsillotomy should be performed. A direct laryngobronchoscopy evaluates airway patency at all levels and is necessary for not only diagnostic evaluation but also therapeutic treatment of the airway. Spontaneous ventilation during this procedure with the tracheostomy removed from 
the airway is paramount to assess any dynamic collapse or obstruction, especially suprastomal collapse and tracheomalacia. Suprastomal granulation tissue, if obstructive, should be removed.

A favorable direct laryngobronchoscopy has been reported as an excellent predictor of successful decannulation. Wirtz et al ${ }^{90}$ published a study of 35 subjects (ages 1-17 y), wherein they recommended direct laryngobronchoscopy with intraoperative decannulation, in the absence of tube downsizing, a capping trial, or PSG. If the airway was deemed adequate at the time of direct laryngobronchoscopy, the tracheostomy tube was removed, and the child was monitored overnight and discharged the following day if no complications arose. Of the 35 decannulated subjects, $54 \%(n=19)$ were discharged the day following decannulation, and 37\% ( $n=13)$ were discharged on post-decannulation day 2. Average in-patient stay for those decannulated was $1.8 \mathrm{~d}$. Of the remaining 3 subjects, one was taken back to the operating room for further excision of a suprastomal granuloma, one was kept for further monitoring due to suprastomal collapse, and one was kept in-patient for non-airway-related issues. All 3 subjects were discharged between post-decannulation days 3 and 5 . However, 2 of these subjects ultimately failed decannulation long-term. One subject had severe obstructive sleep apnea following the tracheocutaneous fistula closure $49 \mathrm{~d}$ after decannulation, and ultimately the tracheostomy was replaced. The second subject also had the tracheostomy replaced $30 \mathrm{~d}$ after decannulation and underwent laryngotracheal reconstruction soon thereafter. Despite the 2 failures, the authors concluded that their protocol offered a conservative approach to resource utilization and that the operative endoscopic examination of the spontaneously breathing patient is a superior evaluation for decannulation.

Role of Capping. The use of capping and downsizing is a common part of many decannulation protocols, although its implementation is not universal. Studies supporting capping report that the reduction and occlusion of tube diameter not only predict decannulation success but also acclimate the child to the changing airway physiology that accompanies tracheostomy tube removal (ie, increased dead space and use of the mouth and nose). Kubba et al ${ }^{94}$ stated that the ability to tolerate a blocked tube during the decannulation process is itself a test of the child's reserve, such that, if they can tolerate the additional obstruction caused by the presence of the tube, they will be more likely to manage without problems on exercise or when they next suffer an upper-respiratory tract infection.

However, a blocked size 3.0 tracheostomy tube will occupy a much greater proportion of the airway in younger children than in older ones; thus, many younger children may not tolerate blocking of the tube. The decreases in the cross-sectional area of the airway in these young children may be to such a degree that those who do not tolerate capping may in fact still tolerate decannulation. Wirtz et al ${ }^{90}$ reported that routine daytime capping is not performed in their decannulation process, because it does not offer an accurate physiologic representation of the decannulated child due to the obstruction of the capped tube. Tunkel et $\mathrm{al}^{91}$ also commented on how a malacic airway may also be stented by a capped tube.

Role of Polysomnogram. The role of capped PSG in the decannulation process has recently gained wider acceptance, although its routine use is debatable. The current literature is composed of retrospective reviews and case series, and there are discrepancies regarding what is termed a favorable PSG when determining candidates for tracheostomy tube removal. Many of those with mild and even moderate obstructive sleep apnea can be decannulated successfully. ${ }^{87,92,93}$

Tracheostomy in children is being performed nowadays for children with fixed laryngotracheal lesions (static upper-airway anatomy) and also those with dynamic airway disorders, including obstructive sleep apnea, tracheomalacia, pharyngeal hypotonia, and associated neuromuscular disorders. Dynamic factors that influence upper-airway patency are usually more apparent during sleep, when muscular tone is decreased. PSG is thus an ideal modality to evaluate for readiness for decannulation; however, evaluation by PSG can be expensive, and pediatric PSGs are not widely available. Nonetheless, it must also be interpreted in light of possible savings achieved by decreasing the number of in-patient ICU days required after decannulation with the use of a favorable PSG. An unfavorable PSG may prevent the morbidity and expense of an unsuccessful decannulation attempt. ${ }^{87,92,93}$ A capped sleep study usually requires the child to first tolerate the tracheostomy capped for between 4 and $6 \mathrm{~h}$ during the day.

Parameters such as apnea-hypopnea index (AHI), obstructive index, and maximal end-tidal $\mathrm{CO}_{2}$ are valuable in predicting successful tracheostomy decannulation. Tunkel et $\mathrm{al}^{91}$ addressed the utility of PSG and showed that PSG provides objective data measuring upper-airway patency during a time when pharyngeal muscle tone is maximally decreased and airway obstruction is at greatest risk. They concluded that an AHI $<1.7$ correlated with successful decannulation. In more recent years, Robison et al ${ }^{87}$ further supported the usefulness of PSG to determine the appropriateness of decannulation. Of the 28 subjects in their study, 20 (71.4\%) were decannulated. The average AHI with a capped tracheostomy for those successfully decannulated was 2.75 (range 0.6-7.6), whereas the AHI for those not decannulated was 15.99 (range 3.2-62). Those who were not decannulated had multiple medical comorbidities, multilevel airway obstruction, need for additional 
surgery, or chronic need for pulmonary toilet. They concluded that PSG may be a useful adjunctive study in the process of determining a patient's readiness for decannulation.

Cristea et $\mathrm{al}^{92}$ reported a series of 189 subjects who were decannulated after a favorable direct laryngobronchoscopy and then had a PSG in the sleep laboratory. Successful (tube not replaced within 6 months) decannulation was achieved in 167 subjects (79.5\%). This study argued against performing a capped PSG due to concerns that the physiologic effects of an indwelling plugged tracheostomy tube must be considered. Infants may not tolerate even the smallest occluded (capped) tracheostomy tube if it creates substantial airway obstruction. An unfavorable study with a capped tube may prevent a successful decannulation in such a case. ${ }^{91}$ In addition, leaving the tracheostomy tube in place in the airway may stent open any underlying areas of malacia and give false assurance that the airway will not collapse, especially during sleep. The pressure dynamics of the airway change following decannulation. The sudden imposition of upper-airway resistance from the nose, tongue, and pharynx can result in significant changes in lower-airway collapsibility. While awake, airway patency is improved. These changes become more pronounced during sleep and, in the case of an abnormal upper airway, can result in varying degrees of obstruction.

Thus, the literature supports that a favorable PSG with tracheostomy capping is complementary to endoscopic assessment in patients with complex airway problems. ${ }^{87,91}$ Overall, the length of ICU admission following decannulation is being decreased secondary to the performance of pre-admission capped sleep studies. Larger studies are needed, however, to validate specific PSG parameter thresholds in all pediatric patients undergoing decannulation. Also, sleep centers with pediatric expertise unfortunately are not available everywhere, and in those that are, there are considerable wait times.

Noninvasive Ventilation. NIV may be used to facilitate decannulation in children who no longer need a tracheostomy for structural upper-airway obstruction but have severe obstructive sleep apnea and/or require nocturnal ventilatory support. NIV can be delivered via nasal prongs or face mask at night following decannulation. Use of NIV is more frequently used in this manner in Europe. Fauroux et al $^{98}$ reported on 15 children (age 2-12 y) in whom decannulation was proposed because endoscopic evaluation showed sufficient upper-airway patency and normal nocturnal gas exchange with a small-size closed tracheal tube, but obstructive airway symptoms occurred either immediately or with a delay after decannulation without noninvasive ventilation. After NIV acclimatization, decannulation was performed with success in all patients. NIV was associated with an improvement in nocturnal gas exchange and marked clinical improvement in their obstructive sleep apnea symptoms. None of the 15 subjects needed tracheostomy recannulation. NIV was withdrawn in 6 subjects after $2-8.5 \mathrm{y}$, and the remaining 9 subjects continued to receive NIV after 1-6y. Thus, in selected patients with obstructive sleep apnea or lung disease, NIV may represent a valuable tool to treat the recurrence of obstructive symptoms after decannulation and may facilitate early weaning from tracheostomy in children who have failed repeated decannulation trials. ${ }^{99}$

\section{Quality Improvement in Tracheostomy Care}

\section{Outcomes of Children With Tracheostomy}

Children have a substantial risk of significant morbidity and mortality following tracheostomy. Studies report that $7-8 \%$ of children do not survive the hospitalization when a tracheostomy is performed.9,19 It is believed the vast majority of deaths following tracheostomy are not tracheostomy-related but rather are secondary to the child's underlying chronic conditions. Guidance to help physicians inform and advise families facing decisions regarding tracheostomy in children with chronic health conditions has been difficult to develop, in part because these children have a heterogeneous array of underlying diagnoses..$^{40,41}$ Up to $60 \%$ of children undergoing tracheostomy have multiple chronic diagnoses affecting different organ systems, which makes counseling of families with good measures of risk and benefit even more difficult. ${ }^{2-5}$ Congenital heart disease, prematurity, the absence of an upper-airway anomaly, and age $<1$ y are characteristics associated with higher mortality in children following tracheostomy. ${ }^{100}$ The highest in-hospital mortality following tracheostomy, reported as $40 \%$, has been observed in premature children who have both neuromuscular impairment and congenital heart disease. $^{3}$

Complications of tracheostomies are well established, with almost $20 \%$ of patients experiencing a tracheostomyrelated complication..$^{9,40}$ Some children experience recurrent hospitalizations because of these complications as well as comorbidities. ${ }^{2,9}$ Complications in the peri-/postoperative period include hemorrhage, infection, pneumothorax, tube obstruction, and accidental decannulation. ${ }^{101,102}$ Later complications include development of granulation tissue, tube obstruction/occlusion, accidental decannulation, bleeding, tracheomalacia, and more rarely tracheoinnominate artery fistula and tracheoesophageal fistula. Although tracheoinnominate artery fistula is reported to occur in $<1 \%$ of all patients undergoing tracheostomy, it is usually fatal. ${ }^{103}$ Nearly $8 \%$ of children do not survive hospital stay when a tracheostomy is placed, with the majority of deaths 
being related to the child's underlying chronic conditions. ${ }^{19,26}$

\section{Defining the Problem}

It is predicted that tracheostomy is a procedure that will be performed with increasing frequency in the future as pediatric ICU care continues to improve and children with complex medical conditions survive longer. Despite this, there has not been a parallel standardization in the quality of care these patients receive. Safe and effective care for a new tracheostomy requires intensive monitoring and care from a variety of providers, including multiple medical specialties, nursing, and ancillary services. For example, communication with and education of the emergency medical staff in the management of tracheostomy emergencies should be mandatory in a community where a child with a tracheostomy resides. This could be provided by the hospital-based tracheostomy teams caring for the child on discharge.

Substantial concerns have been raised regarding suboptimal standards in tracheostomy care, and this is a growing concern in view of the increasing demands for intensive care services. ${ }^{41,42,104}$ In addition, no standardization of protocols for tracheostomy placement and care exists between institutions, making it difficult to benchmark tracheostomy care across institutions. Tracheostomy outcome metrics that exist for adult patients, including time to decannulation and time to wearing a speaking valve, are difficult to adapt to the pediatric population. Also, many of the reported tracheostomy-related events are in fact preventable events and should be amenable to prospective system improvement strategies. ${ }^{105}$

In adults, much is known about the life experience associated with tracheostomy, the potential for adverse outcomes, and associated health-care costs. 5,106,107 There have been a number of single-institution reports in the adult literature addressing the current status of tracheostomy care. There is less in the pediatric literature and also a clear lack of standardization of protocols and policies.

In 2011, Das et al ${ }^{104}$ published the results of surveys of members of the American Academy of OtolaryngologyHead and Neck Surgery, addressing those that had experienced at least one patient with a catastrophic event related to a tracheostomy. There were 253 respondents who described 405 recent catastrophic events related to tracheostomies. Twenty-nine patients were specified to be children, in whom the most commonly reported events were tracheostomy tube occlusion, ${ }^{12}$ decannulation leading to loss of airway, ${ }^{10}$ and tracheoinnominate artery fistula. ${ }^{4} \mathrm{Sev}-$ enteen $(59 \%)$ of the 29 pediatric events were fatal, and 4 resulted in permanent disability. Ten of the 28 events occurred at home.

Although a survey methodology was used in this study and there is a high possibility of both response bias and recall bias, it is very possible that the number of events was underestimated because there are a number of pediatric patients who may die from tracheostomy-related complications at home or are lost to follow up. A companion paper by the same group also reported significant variability in ongoing surveillance and care of tracheostomy patients. ${ }^{42}$

National studies on pediatric tracheostomy have reported an overall mortality rate of nearly $8 \% .^{9,19}$ A retrospective study using the Truven Medicaid MarketScan Database reported on 502 children (0-16 y) in Medicaid from 10 states who underwent tracheostomy in 2009 and were followed through 2011.40 Median age at tracheostomy was 8 y (interquartile range 1-16 y). As evidenced in other studies, ${ }^{2-5}$ the children in the cohort were very medically complex. Two-year rates of in-hospital mortality and tracheostomy complication (excluding the admission when the tracheostomy was placed) were 8.9 and $38.8 \%$, respectively. In this study, children of younger age $(<1 \mathrm{y})$ at the time of tracheostomy placement, children of Hispanic ethnicity, and children with more complex chronic condition type all had increased likelihood of death. Of the children who had a tracheostomy complication (38.8\%), mortality was low $(4.1 \%)$, suggesting again that death in all children was not tracheostomy-related in the majority of patients. Health-care spending was also addressed in this study, and total spending in the $2 \mathrm{y}$ following tracheostomy for the 502 children was $\$ 53.3$ million, with hospital, home, and primary care constituting $64.4,9.4$, and $0.5 \%$ of total spending, respectively.

An analysis of the American College of Surgeons National Surgical Quality Improvement Program Pediatric performed by Mahida et $\mathrm{al}^{28}$ demonstrated that the highest contribution to composite morbidity in otolaryngology is seen in children younger than $2 \mathrm{y}$ undergoing tracheostomy. The National Surgical Quality Improvement Program Pediatric reports predefined 30-d postoperative outcomes for surgical cases from participating institutions for quality improvement. The study attempted to determine predictive factors for complications following tracheostomy placement in patients younger than $2 \mathrm{y}$ that, if targeted for reduction in quality initiatives, might result in improved surgical outcomes. Of the 206 children younger than 2 y who underwent elective tracheostomy from 2012 to 2013 among 61 participating institutions, $24.3 \%$ experienced a major complication within $30 \mathrm{~d}$. The most common complications were pneumonia $(7.8 \%)$, postoperative sepsis $(5.8 \%)$, death $(5.8 \%)$, and deep or organ space surgical site infections $(3.9 \%)$.

\section{Multidisciplinary Team Approach}

Due to their medical complexity, children with tracheostomy are usually cared for by an array of medical pro- 
viders and care teams, including otorhinolaryngologists, pulmonologists, cardiologists, neurologists, primary care physicians, nurses, respiratory therapists, and equipment specialists. Unfortunately, the majority of these patients experience extremely disorganized, fragmented care and poor communication between providers, which continue to be obstacles to optimal patient outcomes. It has been demonstrated that care can be dramatically improved and tracheostomy-related adverse events can be radically reduced through implementation of tracheostomy care teams. ${ }^{108-111}$ Tracheostomy teams enhance consistency of patient care and promote implementation of standardized protocols of care.

Over the last decade, a few adult institutions have shown that with truly integrated multidisciplinary tracheostomy care, it is possible to radically reduce adverse events and significantly improve care for patients with tracheostomy. ${ }^{109,112,113}$ In 2009, Cameron et al ${ }^{114}$ reported that implementation of a tracheostomy review and management service program resulted in significantly improved outcomes, with patients having a shorter length of hospital stay (median stay decreased from 60 to $41.5 \mathrm{~d}$ ), vocalizing earlier and more often (speaking valve usage increased from 35 to $82 \%$ ), and having a shorter time to decannulation (median decrease of decannulation from 22.5 to 16.5 d). Significantly, annual cost savings were also 8 times greater than the cost of program provision.

In 2011, Hettige et al ${ }^{110}$ reported a multidisciplinary care model consisting of a tracheostomy bundle with 3 components: a checklist, a dedicated tracheostomy multidisciplinary team, and an educational program. These interventions were associated with an $88 \%$ reduction in critical incidents, shorter ICU stay, and shorter time to decannulation (decrease from a mean of 21 to $11 \mathrm{~d}$ ).

Welton et al, ${ }^{115}$ subsequently reported that following implementation of the interprofessional tracheostomy team, there was no improvement in decannulation times or time from weaning to speech-language pathology referral. However, a significant improvement was noted in the average time to first tracheostomy tube change (from 36.2 to $22.9 \mathrm{~d}$, $P=.01)$ and average time to speech-language pathology referral following initial tracheostomy insertion (51.8 to $26.3 \mathrm{~d}, P=.01$ ). They concluded that a multidisciplinary tracheostomy team can improve the quality of tracheostomy care through earlier tracheostomy tube changes and swallowing assessment referrals. The authors commented that the lack of improved weaning to decannulation time was potentially due to poor adherence with established protocols as well as a change in mechanical ventilation practices.

Most of these reports are with respect to adult tracheostomy care, and unfortunately there has not been as much reported progress in the pediatric tracheostomy literature. Abode et al ${ }^{111}$ demonstrated that a multidisciplinary ap- proach can yield measurable improvements in important outcomes. Their study had 3 primary aims: (1) optimize stay for children with newly placed tracheostomies,(2) improve communication among providers and caregivers, and (3) avoid tracheostomy complications. They instituted and tracked initiatives (2007-2013), including an enhanced tracheostomy education program and weekly clinical care conferences, and also developed and implemented institutional consensus of care for aspects of care currently lacking published evidence-based or expert guidelines. In children $<1$ y of age, the mean stay from 2007 to 2013 was reduced from 36 to $27 \mathrm{~d}$ for those discharged to home. A consensus-driven decannulation protocol resulted in successful decannulation in $71 \%$ of initial attempts and $86 \%$ of overall attempts of decannulation. The authors recommended that institutions with multidisciplinary pediatric airway programs should adapt structure, processes, and goals to individual institutional strengths, barriers, and resources.

\section{Standardization of Protocols and Policies}

United Kingdom National Tracheostomy Safety Project. The United Kingdom National Tracheostomy Safety Project primarily aimed to improve management of tracheostomy critical incidents through the development of emergency algorithms that describe a universal approach to management of adult and pediatric tracheostomy emergencies. ${ }^{116}$ Tracheostomy education for both providers and patients was addressed through standardized resources in the form of self-directed learning modules.

International Pediatric Otolaryngology Group. In 2016, the International Pediatric Otolaryngology Group published consensus recommendations for perioperative tracheostomy care in pediatric patients, aimed at improving patient-centered care in this patient population. ${ }^{117}$ The recommendations were formed through expert opinion by the members of the group and are targeted to pediatric patients with newly placed tracheostomies and include (1) preoperative considerations, (2) intraoperative considerations, (3) comprehensive postoperative care algorithm, (4) sedation algorithm, (5) enteral feeding algorithm, and (6) tracheostomy bedside information sheet. Although there are no studies validating the outcome of these recommendations to date, they are an important step in proposing standardization of pediatric tracheostomy care.

Global Tracheostomy Collaborative. Although a small number of hospitals have demonstrated that it is possible to reduce adverse events substantially, in some cases by 5 -fold or more, the system-wide changes that led to these improvements are not easy to implement and have not been rapidly adopted by other hospitals. The slow diffu- 
sion of medical and health-care innovation is widely recognized ${ }^{118}$; one approach to overcome this delay is a quality improvement collaborative.

The Global Tracheostomy Collaborative, formed in 2014, is a multi-institutional, multidisciplinary organization with the objective of improving the care and safety care of children and adults with tracheostomies worldwide (http://globaltrach.org, Accessed October 14, 2016). The collaborative consists of a multidisciplinary group of providers, patients, physicians, nurses, respiratory therapists, allied health professionals, and patients/caregivers and families from 9 countries working to delineate and disseminate best practices surrounding tracheostomy care. This is accomplished in part by utilizing a prospective multi-institutional database to gather data on patients undergoing tracheostomy. Specifically, the Global Tracheostomy Collaborative promotes a number of key drivers that are known to be associated with improvement that include: (1) truly multidisciplinary effectively coordinated multidisciplinary care teams, (2) institutionwide protocols, (3) broad staff education, (4) patient and family involvement, and (5) data analysis.

The Global Tracheostomy Collaborative aims to improve outcomes in tracheostomy care. One of its key drivers in achieving that goal is the development of best practices and standardization of care. Prospectively collecting outcome data on a large scale via an international, multiinstitutional HIPAA-compliant database will eventually allow for benchmarks to be set and for novel targets for quality improvement initiatives to be identified. ${ }^{119}$ This will help to define and refine tracheostomy care best practices. The database contains branching logic to collect data specific to both adult and pediatric patients with tracheostomy. Variables collected include demographics, clinical characteristics, indication for tracheostomy, stay in ICU, duration of mechanical ventilation, time to decannulation, and adverse events. The purpose of the database is to allow hospitals to track their own progress and ultimately to allow hospitals to benchmark themselves against their peers (anonymously). To date, the database has recorded the data of $>1,500$ patients with tracheostomy since August 2015, and member hospitals receive biannual reports of their data. ${ }^{119}$ As the use of this collaborative database grows, tracheostomy care best practices can be refined and disseminated, and new targets for quality improvement may be identified.

\section{Summary}

Tracheostomy is being increasingly performed in pediatric patients. The indications for tracheostomy and the characteristics of children with tracheostomy have changed significantly over the last 50 years, reflecting the changes that have occurred in the management of critically ill children. Prolonged invasive ventilation is now the primary indication for tracheostomy in children, but the definition of time when the tracheostomy should be placed remains highly variable, between 14 and $90 \mathrm{~d}$ in some studies, and most consider that timing should be made on an individual patient basis. The open surgical technique continues to remain the optimal technique for tracheostomy in children. The role of percutaneous tracheostomy in children is not yet clearly defined, but it may be feasible in older children.

The optimal pediatric decannulation protocol supports tube downsizing and daytime capping, in addition to a favorable capped PSG and endoscopic airway assessment (direct laryngobronchoscopy) as a strong predictor of successful decannulation. As a result of the increased use of capped PSGs, the length of ICU admission following decannulation can be decreased in those children receiving favorable capped sleep studies. However, larger studies are needed to validate specific favorable PSG parameter thresholds in pediatric patients undergoing decannulation.

Tracheostomy care in children is a complex, truly multidisciplinary process. It is widely recognized that patients with tracheostomy are at high risk for potentially preventable adverse events that can lead to significant morbidity and even mortality, and there is a recognized need for improvement of care. Future directions include multiinstitutional analyses of care coordination and transitions for pediatric tracheostomy patients as well as testing the effectiveness of interventions such as multidisciplinary tracheostomy care teams, standardized tracheostomy protocols and policies, broad staff education, and family involvement. These factors will be key to improving the quality of care for these patients. In response to globally identified recurrent themes that have led to measurable harm and a clear need to accelerate the spread of improvements in tracheostomy care, an international, multidisciplinary quality improvement collaborative aimed at improving outcomes for both adult and pediatric patients with tracheostomy has been established.

\section{REFERENCES}

1. Arcand P, Granger J. Pediatric tracheostomies: changing trends. J Otolaryngol 1988;17(2):121-124.

2. Graf JM, Montagnino BA, Hueckel R, McPherson ML. Pediatric tracheostomies: a recent experience from one academic center. Pediatr Crit Care Med 2008;9(1):96-100.

3. Berry JG, Graham RJ, Roberson DW, Rhein L, Graham DA, Zhou $\mathrm{J}$, et al. Patient characteristics associated with in-hospital mortality in children following tracheotomy. Arch Dis Child 2010;95(9):703710.

4. Liu C, Heffernan C, Saluja S, Yuan J, Paine M, Oyemwense N, et al. Indications, hospital course, and complexity of patients undergoing tracheostomy at a tertiary care pediatric hospital. Otolaryngol Head Neck Surg 2014;151(2):232-239.

5. Goldenberg D, Ari EG, Danino J, Netzer A, Joachims HZ. Tracheotomy complications: a retrospective study of 1130 cases. Otolaryngol Head Neck Surg 2000;123(4):495-500. 
6. Graham RJ, Rodday AM, Parsons SK. Family-centered assessment and function for children with chronic mechanical respiratory support. J Pediatr Health Care 2014;28(4):295-304.

7. Glass KC, Carnevale FA. Decisional challenges for children requiring assisted ventilation at home. HEC Forum 2006;18(3):207-221.

8. Lindahl B, Lindblad BM. Family members' experiences of everyday life when a child is dependent on a ventilator: a metasynthesis study. J Fam Nurs 2011;17(2):241-269.

9. Berry JG, Graham DA, Graham RJ, Zhou J, Putney HL, O'Brien JE, et al. Predictors of clinical outcomes and hospital resource use of children after tracheotomy. Pediatrics 2009;124(2):563-572.

10. Mahadevan M, Barber C, Salkeld L, Douglas G, Mills N. Pediatric tracheotomy: 17 year review. Int J Pediatr Otorhinolaryngol 2007; 71(12):1829-1835.

11. French LC, Wootten CT, Thomas RG, Neblett WW 3rd, Werkhaven JA, Cofer SA. Tracheotomy in the preschool population: indication and outcomes. Otolaryngol Head Neck Surg 2007;137(2):280-283.

12. Ozmen S, Ozmen OA, Unal OF. Pediatric tracheotomies: a 37-year experience in 282 children. Int J Pediatr Otorhinolaryngol 2009; 73(7):959-961

13. de Trey L, Niedermann E, Ghelfi D, Gerber A, Gysin C. Pediatric tracheotomy: a 30-year experience. J Pediatr Surg 2013;48(7):14701475.

14. Tantinikorn W, Alper CM, Bluestone CD, Casselbrant ML. Outcome in pediatric tracheotomy. Am J Otolaryngol 2003;24(3):131137.

15. Leung R, Berkowitz RG. Decannulation and outcome following pediatric tracheostomy. Ann Otol Rhinol Laryngol 2005;114(10): 743-748

16. Carron JD, Derkay CS, Strope GL, Nosonchuk JE, Darrow DH. Pediatric tracheotomies: changing indications and outcomes. Laryngoscope 2000;110(7):1099-1104.

17. Goodall EW. On infectious diseases and epidemiology in the Hippocratic collection: (Section of the History of Medicine). Proc R Soc Med 1934;27(5):525-534.

18. Jackson C. Tracheotomy. Laryngoscope 1909;19:285-290.

19. Lewis CW, Carron JD, Perkins JA, Sie KC, Feudtner C. Tracheotomy in pediatric patients: a national perspective. Arch Otolaryngol Head Neck Surg 2003;129(5):523-529.

20. Hadfield PJ, Lloyd-Faulconbridge RV, Almeyda J, Albert DM, Bailey CM. The changing indications for paediatric tracheostomy. Int J Pediatr Otorhinolaryngol 2003;67(1):7-10.

21. Line WS Jr., Hawkins DB, Kahlstrom EJ, MacLaughlin EF, Ensley JL. Tracheotomy in infants and young children: the changing perspective 1970-1985. Laryngoscope 1986;96(5):510-515.

22. Dursun O, Ozel D. Early and long-term outcome after tracheostomy in children. Pediatr Int 2011;53(2):202-206.

23. Kraft S, Patel S, Sykes K, Nicklaus P, Gratny L, Wei JL. Practice patterns after tracheotomy in infants younger than 2 years. Arch Otolaryngol Head Neck Surg 2011;137(7):670-674.

24. Lawrason A, Kavanagh K. Pediatric tracheotomy: are the indications changing? Int J Pediatr Otorhinolaryngol 2013;77(6):922-925.

25. Sidman JD, Jaguan A, Couser RJ. Tracheotomy and decannulation rates in a level 3 neonatal intensive care unit: a 12-year study. Laryngoscope 2006;116(1):136-139.

26. Zhu H, Das P, Roberson DW, Jang J, Skinner ML, Paine M, et al. Hospitalizations in children with preexisting tracheostomy: a national perspective. Laryngoscope 2015;125(2):462-468.

27. Deutsch ES. Tracheostomy: pediatric considerations. Respir Care 2010;55(8):1082-1090.

28. Mahida JB, Asti L, Boss EF, Shah RK, Deans KJ, Minneci PC, Jatana KR. Tracheostomy placement in children younger than 2 years: 30-day outcomes using the National Surgical Quality Im- provement Program Pediatric. JAMA Otolaryngol Head Neck Surg 2016;142(3):241-246.

29. Wood D, McShane P, Davis P. Tracheostomy in children admitted to paediatric intensive care. Arch Dis Child 2012;97(10):866-869.

30. Veenith T, Ganeshamoorthy S, Standley T, Carter J, Young P. Intensive care unit tracheostomy: a snapshot of UK practice. Int Arch Med 2008;1(1):21.

31. Agency for Healthcare Research and Quality. https://www.hcupus.ahrq.gov/reports/statbriefs/sb187-Hospital-Stays-Children2012.pdf. Accessed April 25, 2017.

32. Freeman BD, Morris PE. Tracheostomy practice in adults with acute respiratory failure. Crit Care Med 2012;40(10):2890-2896.

33. Durbin CG Jr., Perkins MP, Moores LK. Should tracheostomy be performed as early as 72 hours in patients requiring prolonged mechanical ventilation? Respir Care 2010;55(1):76-87.

34. Andriolo BN, Andriolo RB, Saconato H, Atallah AN, Valente O. Early versus late tracheostomy for critically ill patients. Cochrane Database Syst Rev 2015;(1):CD007271.

35. Lee W, Koltai P, Harrison AM, Appachi E, Bourdakos D, Davis S, et al. Indications for tracheotomy in the pediatric intensive care unit population: a pilot study. Arch Otolaryngol Head Neck Surg 2002; 128(11):1249-1252.

36. Wakeham MK, Kuhn EM, Lee KJ, McCrory MC, Scanlon MC. Use of tracheostomy in the PICU among patients requiring prolonged mechanical ventilation. Intensive Care Med 2014;40(6):863-870.

37. Principi T, Morrison GC, Matsui DM, Speechley KN, Seabrook JA, Singh RN, Kornecki A. Elective tracheostomy in mechanically ventilated children in Canada. Intensive Care Med 2008;34(8):14981502 .

38. Edwards JD, Houtrow AJ, Lucas AR, Miller RL, Keens TG, Panitch HB, Dudley RA. Children and young adults who received tracheostomies or were initiated on long-term ventilation in PICUs. Pediatr Crit Care Med 2016;17(8):e324-e334.

39. Holloway AJ, Spaeder MC, Basu S. Association of timing of tracheostomy on clinical outcomes in PICU patients. Pediatr Crit Care Med 2015;16(3):e52-e58.

40. Watters K, O’Neill M, Zhu H, Graham RJ, Hall M, Berry J. Twoyear mortality, complications, and healthcare use in children with medicaid following tracheostomy. Laryngoscope 2016;126(11): 2611-2617.

41. Berry JG, Goldmann DA, Mandl KD, Putney H, Helm D, O'Brien $\mathrm{J}$, et al. Health information management and perceptions of the quality of care for children with tracheotomy: a qualitative study. BMC Health Serv Res 2011;11:117.

42. Zhu H, Das P, Brereton J, Roberson D, Shah RK. Surveillance and management practices in tracheotomy patients. Laryngoscope 2012; 122(1):46-50.

43. Prescott CA, Vanlierde MJ. Tracheostomy in children: the Red Cross War Memorial Children's Hospital experience 1980-1985. Int J Pediatr Otorhinolaryngol 1989;17(2):97-107.

44. Carr MM, Poje CP, Kingston L, Kielma D, Heard C. Complications in pediatric tracheostomies. Laryngoscope 2001;111(11 Pt 1):19251928.

45. Carter P, Benjamin B. Ten-year review of pediatric tracheotomy. Ann Otol Rhinol Laryngol 1983;92(4 Pt 1):398-400.

46. Holinger PH, Brown WT, Maurizi DG. Tracheostomy in the newborn. Am J Surg 1965;109;771-779.

47. Monnier P. Applied surgical anatomy of the larynx and trachea. In: Monnier P, editor. Pediatric airway surgery: management of laryngotracheal stenosis in infants and children. Berlin: Springer-Verlag; 2011:7-100.

48. Henick DH, Holinger LD. Laryngeal development. In: Holinger LD, Lusk RP, Green CG, editors. Pediatric laryngology and bron- 
choesophagoscopy. Philadelphia, Pennsylvania: Lippincott- Raven; 1997:1-17.

49. Laitman JT. The anatomy of human speech. Natural History 1984; 93:20-27.

50. Jackson C. High tracheostomy and other errors: the chief causes of chronic laryngeal stenosis. Surg Gynecol Obstet 1921;32:392-398.

51. Ciaglia P, Graniero KD. Percutaneous dilatational tracheostomy. Results and long-term follow-up. Chest 1992;101(2):464-467.

52. Putensen C, Theuerkauf N, Guenther U, Vargas M, Pelosi P. Percutaneous and surgical tracheostomy in critically ill adult patients: a meta-analysis. Crit Care 2014;18(6):544-565.

53. Kost KM. Endoscopic percutaneous dilatational tracheotomy: a prospective evaluation of 500 consecutive cases. Laryngoscope 2005; 115(10 Pt 2):1-30.

54. Vigliaroli L, De Vivo P, Mione C, Pretto G. Clinical experience with Ciaglia's percutaneous tracheostomy. Eur Arch Otorhinolaryngol 1999;256(8):426-428.

55. Scott CJ, Darowski M, Crabbe DC. Complications of percutaneous dilatational tracheostomy in children. Anaesthesia 1998;53(5):477480.

56. Toursarkissian B, Fowler CL, Zweng TN, Kearney PA. Percutaneous dilational tracheostomy in children and teenagers. J Pediatr Surg 1994;29(11):1421-1424.

57. Zawadzka-Glos L, Rawicz M, Chmielik M. Percutaneous tracheotomy in children. Int J Pediatr Otorhinolaryngol 2004;68(11):13871390.

58. Baek CH, Chung YJ, Jeong HS, Kim SW. Comparison of open dilatational tracheostomy with conventional pediatric tracheostomy in a growing animal model. Laryngoscope 2005;115(12):2193-2198.

59. Raju A, Joseph DK, Diarra C, Ross SE. Percutaneous versus open tracheostomy in the pediatric trauma population. Am Surg 2010; 76(3):276-278

60. Gollu G, Ates U, Can OS, Kendirli T, Yagmurlu A, Cakmak M, et al. Percutaneous tracheostomy by Griggs technique under rigid bronchoscopic guidance is safe and feasible in children. J Pediatr Surg 2016;51(10): 1635-1639.

61. Gallagher TQ, Hartnick CJ. Pediatric tracheotomy. Adv Otorhinolaryngol 2012;73:26-30.

62. Song JJ, Choi IJ, Chang H, Kim DW, Chang HW, Park GH, et al. Pediatric tracheostomy revisited: a nine-year experience using horizontal intercartilaginous incision. Laryngoscope 2015;125(2):485492.

63. Fry TL, Jones RO, Fischer ND, Pillsbury HC. Comparisons of tracheostomy incisions in a pediatric model. Ann Otol Rhinol Laryngol 1985;94(5 Pt 1):450-453.

64. Norwood S, Vallina VL, Short K, Saigusa M, Fernandez LG, McLarty JW. Incidence of tracheal stenosis and other late complications after percutaneous tracheostomy. Ann Surg 2000;232(2): 233-241.

65. Mendez-Picon G, Ehrlich FE, Salzberg AM. The effect of tracheostomy incision on tracheal growth. J Pediatr Surg 1976;11(5):681685.

66. MacRae DL, Rae RE, Heeneman H. Pediatric tracheotomy. J Otolaryngol 1984;13(5):309-311.

67. Ruggiero FP, Carr MM. Infant tracheotomy: results of a survey regarding technique. Arch Otolaryngol Head Neck Surg 2008; 134(3):263-267.

68. Craig MF, Bajaj Y, Hartley BE. Maturation sutures for the paediatric tracheostomy: an extra safety measure. J Laryngol Otol 2005; 119(12):985-987.

69. Waki EY, Madgy DN, Zablocki H, Belenky WM, Hotaling AJ. An analysis of the inferior based tracheal flap for pediatric tracheotomy. Int J Pediatr Otorhinolaryngol 1993;27(1):47-54.
70. Koltai PJ. Starplasty: a new technique of pediatric tracheotomy. Arch Otolaryngol Head Neck Surg 1998;124(10):1105-1111.

71. Park JY, Suskind DL, Prater D, Muntz HR, Lusk RP. Maturation of the pediatric tracheostomy stoma: effect on complications. Ann Otol Rhinol Laryngol 1999;108(12):1115-1119.

72. Colman KL, Mandell DL, Simons JP. Impact of stoma maturation on pediatric tracheostomy-related complications. Arch Otolaryngol Head Neck Surg 2010;136(5):471-474.

73. Bjork VO. Partial resection of the only remaining lung with the aid of respirator treatment. J Thorac Cardiovasc Surg 1960;29:179-188.

74. Eliachar I, Zohar S, Golz A, Joachims HZ, Goldsher M. Permanent tracheostomy. Head Neck Surg 1984;7(2):99-103.

75. Solares CA, Krakovitz P, Hirose K, Koltai PJ. Starplasty: revisiting a pediatric tracheostomy technique. Otolaryngol Head Neck Surg 2004;131(5):717-722.

76. McNamara DG, Asher MI, Rubin BK, Stewart A, Byrnes CA. Heated humidification improves clinical outcomes, compared to a heat and moisture exchanger in children with tracheostomies. Respir Care 2014;59(1):46-53.

77. Kaslon KW, Stein RE. Chronic pediatric tracheotomy: assessment and implications for habilitation of voice, speech and language in young children. Int J Pediatr Otorhinolaryngol 1985;9(2):165-171.

78. Suiter DM, McCullough GH, Powell PW. Effects of cuff deflation and one-way tracheostomy speaking valve placement on swallow physiology. Dysphagia 2003;18(4):284-292.

79. Hull EM, Dumas HM, Crowley RA, Kharasch VS. Tracheostomy speaking valves for children: tolerance and clinical benefits. Pediatr Rehabil 2005;8(3):214-219.

80. Buswell C, Powell J, Powell S. Paediatric tracheostomy speaking valves: our experience of forty-two children with an adapted PassyMuir speaking valve. Clin Otolaryngol 2016. doi: 10.1111/coa. 12776. [Epub ahead of print].

81. Cho Lieu JE, Muntz HR, Prater D, Blount Stahl M. Passy-Muir valve in children with tracheotomy. Int J Pediatr Otorhinolaryngol 1999;50(3):197-203.

82. Green NM. Fatal cardiovascular and respiratory failure associated with tracheostomy. N Engl J Med 1959;261;846-848.

83. Hawkins DB, Williams EH. Tracheostomy in infants and young children. Laryngoscope 1976;86(3):331-340.

84. Wetmore RF, Marsh RR, Thompson ME, Tom LW. Pediatric tracheostomy: a changing procedure? Ann Otol Rhinol Laryngol 1999; 108(7 Pt 1):695-699.

85. Pérez-Ruiz E, Caro P, Pérez-Frías J, Cols M, Barrio I, Torrent A, et al. Paediatric patients with a tracheostomy: a multicentre epidemiological study. Eur Respir J 2012;40(6):1502-1507.

86. Mitchell RB, Hussey HM, Setzen G, Jacobs IN, Nussenbaum B, Dawson $\mathrm{C}$, et al. Clinical consensus statement: tracheostomy care. Otolaryngol Head Neck Surg 2013;148(1):6-20.

87. Robison JG, Thottam PJ, Greenberg LL, Maguire RC, Simons JP, Mehta DK. Role of polysomnography in the development of an algorithm for planning tracheostomy decannulation. Otolaryngol Head Neck Surg 2015;152(1):180-184.

88. Prickett KK, Sobol SE. Inpatient observation for elective decannulation of pediatric patients with tracheostomy. JAMA Otolaryngol Head Neck Surg 2015;141(2):120-125.

89. Funamura JL, Durbin-Johnson B, Tollefson TT, Harrison J, Senders CW. Pediatric tracheotomy: indications and decannulation outcomes. Laryngoscope 2014;124(8):1952-1958.

90. Wirtz N, Tibesar RJ, Lander T, Sidman J. A pediatric decannulation protocol: outcomes of a 10-year experience. Otolaryngol Head Neck Surg 2016;154(4):731-734 
91. Tunkel DE, McColley SA, Baroody FM, Marcus CL, Carroll JL, Loughlin GM. Polysomnography in the evaluation of readiness for decannulation in children. Arch Otolaryngol Head Neck Surg 1996; 122(7):721-724

92. Cristea AI, Jalou HE, Givan DC, Davis SD, Slaven JE, Ackerman VL. Use of polysomnography to assess safe decannulation in children. Pediatr Pulmonol 2016;51(8):796-802.

93. Gurbani N, Promyothin U, Rutter M, Fenchel MC, Szczesniak RD, Simakajornboon N. Using polysomnography and airway evaluation to predict successful decannulation in children. Otolaryngol Head Neck Surg 2015;153(4):649-655.

94. Kubba H, Cooke J, Hartley B. Can we develop a protocol for the safe decannulation of tracheostomies in children less than 18 months old? Int J Pediatr Otorhinolaryngol 2004;68(7):935-937.

95. Mukherjee B, Bais AS, Bajaj Y. Role of polysomnography in tracheostomy decannulation in the paediatric patient. J Laryngol Otol 1999;113(5):442-445.

96. Waddell A, Appleford R, Dunning C, Papsin BC, Bailey CM. The Great Ormond Street protocol for ward decannulation of children with tracheostomy: increasing safety and decreasing cost. Int J Pediatr Otorhinolaryngol 1997;39(2):111-118.

97. Merritt RM, Bent JP, Smith RJ. Suprastomal granulation tissue and pediatric tracheotomy decannulation. Laryngoscope 1997;107(7): 868-871.

98. Fauroux B, Leboulanger N, Roger G, Denoyelle F, Picard A, Garabedian EN, Aubertin G, Clément A. Noninvasive positive-pressure ventilation avoids recannulation and facilitates early weaning from tracheotomy in children. Pediatr Crit Care Med 2010;11(1): 31-37.

99. Graf JM. Early decannulation of the pediatric patient from tracheostomy to noninvasive positive pressure ventilation: teamwork and patience. Pediatr Crit Care Med 2010;11(1):146-147.

100. Funamura JL, Yuen S, Kosuke K, Gergin O, Adil E, Rahbar R, Watters K. Characterizing mortality in pediatric tracheostomy patients. Laryngoscope 2016. doi: 10.1002/lary.26361 [Epub ahead of print].

101. Myers EN, Carrau RL. Early complications of tracheotomy: incidence and management. Clin Chest Med 1991;12(3):589-595.

102. Feller-Kopman D. Acute complications of artificial airways. Clin Chest Med 2003;24(3):445-455.

103. Epstein SK. Late complications of tracheostomy. Respir Care 2005; 50(4):542-549.

104. Das P, Zhu H, Shah RK, Roberson DW, Berry J, Skinner ML. Tracheotomy-related catastrophic events: results of a national survey. Laryngoscope 2012;122(1):30-37.

105. McGrath BA, Thomas AN. Patient safety incidents associated with tracheostomies occurring in hospital wards: a review of reports to the UK National Patient Safety Agency. Postgrad Med J 2010; 86(1019):522-525

106. Halum SL, Ting JY, Plowman EK, Belafsky PC, Harbarger CF, Postma GN, Merati AL. A multi-institutional analysis of tracheotomy complications. Laryngoscope 2012;122(1):38-45.
107. Shah RK, Lander L, Berry JG, Nussenbaum B, Merati A, Roberson DW. Tracheotomy outcomes and complications: a national perspective. Laryngoscope 2012;122(1):25-29.

108. Garrubba M, Turner T, Grieveson C. Multidisciplinary care for tracheostomy patients: a systematic review. Crit Care 2009;13(6): R177.

109. Cetto R, Arora A, Hettige R, Nel M, Benjamin L, Gomez CM, et al Improving tracheostomy care: a prospective study of the multidisciplinary approach. Clin Otolaryngol 2011;36(5):482-488.

110. Hettige R, Arora A, Ifeacho S, Narula A. Improving tracheostomy management through design, implementation and prospective audit of a care bundle: how we do it. Clin Otolaryngol 2008;33(5):488491.

111. Abode KA, Drake AF, Zdanski CJ, Retsch-Bogart GZ, Gee AB, Noah TL. A multidisciplinary children's airway center: impact on the care of patients with tracheostomy. Pediatrics 2016;137(2): e20150455.

112. McGrath BA, Calder N, Laha S, Perks A, Chaudry I, Bates L, Moore JA, Atkinson D. Reduction in harm from tracheostomyrelated patient safety incidents following introduction of the National Tracheostomy Safety Project: our experience from two hundred and eighty-seven incidents. Clin Otolaryngol 2013;38(6): 541-545.

113. Pandian V, Miller CR, Mirski MA, Schiavi AJ, Morad AH, Vaswani RS, et al. Multidisciplinary team approach in the management of tracheostomy patients. Otolaryngol Head Neck Surg 2012;147(4): 684-691.

114. Cameron TS, McKinstry A, Burt SK, Howard ME, Bellomo R, Brown DJ, et al. Outcomes of patients with spinal cord injury before and after introduction of an interdisciplinary tracheostomy team. Crit Care Resusc 2009;11(1):14-19.

115. Welton C, Morrison M, Catalig M, Chris J, Pataki J. Can an interprofessional tracheostomy team improve weaning to decannulation times? A quality improvement evaluation. Can J Respir Ther 2016; 52(1):7-11.

116. McGrath BA, Bates L, Atkinson D, Moore JA. Multidisciplinary guidelines for the management of tracheostomy and laryngectomy airway emergencies. Anaesthesia 2012;67(9):1025-1041.

117. Strychowsky JE, Albert D, Chan K, Cheng A, Daniel SJ, De Alarcon A, et al. International Pediatric Otolaryngology Group (IPOG) consensus recommendations: routine peri-operative pediatric tracheotomy care. Int J Pediatr Otorhinolaryngol 2016; $86: 250-255$

118. Nadeem E, Olin SS, Hill LC, Hoagwood KE, Horwitz SM. Understanding the components of quality improvement collaboratives: a systematic literature review. Milbank Q 2013;91(2):354-394.

119. Lavin J, Shah R, Greenlick H, Gaudreau P, Bedwell J. The Global Tracheostomy Collaborative: one institution's experience with a new quality improvement initiative. Int J Pediatr Otorhinolaryngol 2016;80:106-108.

\section{Discussion}

Berlinski: Thank you for your presentation. I have a couple of comments, and there's a common theme to both. First is: Do you really practice an interdisciplinary discussion before a trach is placed? My experience has been that the process of tracheostomy lasts $7 \mathrm{~d}$ for the intensivist (as long as they stay in the ICU), a few hours for the surgeon during the placement and the follow-up, and for up to $18 \mathrm{y}$ or more for us (pediatric pulmonologists) when there is chronic ventilatory dependence or chronic lung disease present. Many times we are not invited to the pre-tracheostomy discussion; we are called after the fact. Sometimes the same thing happens with the decannulation process because you alluded to a group that has upper-airway obstruction and doesn't have chronic lung disease. That probably doesn't require much conversation. Sometimes I see disconnect between the surgeon and the pulmonologist 
as to why the patient should still have a tracheostomy. I would like to hear your thoughts.

Watters: I agree, a lot of the multidisciplinary teamwork we've focused on has all been after the tracheostomy is placed, around care at home and in the community. I think there are a lot of issues with regards to the actual decision-making process of whether a tracheostomy is indicated or not. I will say, however, that it is very rare that a tracheostomy is ever placed in a child after $7 \mathrm{~d}$ of intubation, but as a surgeon, I know we are usually just consulted to come up and schedule placement of the tracheostomy, without being involved in the process/discussion of whether the tracheostomy is truly indicated. I really think that is an area that needs to be improved. Plus, we have no consensus, for example, if you focus on the premature population, as to the timing of when the tracheostomy should be placed. One of the reasons why we do not want to place the tracheostomy too early is the known associated mortality of children with a tracheostomy and also the care of a child in the community with a tracheostomy, which can be highly variable. Some children are intubated for up to 8 or 12 weeks before we are consulted for tracheostomy placement. I think recurrent attempts of extubation are made, to try to avoid a tracheostomy. After 3 or 4 failed extubations, it becomes clear that a tracheostomy should be considered. However, there is no consensus as to the length of time a child should be intubated. I think a lot of it depends on the associated comorbidities that the child has, and taking into account children with neuromuscular disorders, it often becomes an ethical situation as well: Is placing a tracheostomy in this child the right thing to do?

Panitch: Getting back to the preterm population, there are some data from large databases that suggest tracheos- tomy is associated with worse outcome. But that may be because the trach is a marker for severe disease as opposed to the cause. Those are children who have chronic lung disease who require long-term mechanical ventilation. The flip side of that is that development may be hampered by not performing a tracheostomy a little earlier because the infant needs to be restrained so that he or she doesn't pull out an ETT. The infants are confined to bed, they can't work as well with rehabilitation specialists, and so I think that there is a need for a more thoughtful approach to identify which infants you would anticipate are going to need long-term ventilation and perhaps go to earlier tracheostomy to enhance development while they're still in the NICU.

Watters: I would agree with that.

Walsh: Just to add on, it seems like with us getting better at NIV, I do think those multidisciplinary discussions are happening in that patient population. In other words, we've sent them home receiving NIV, and they continued to fail or have issues, and then the pulmonologist is involved and the hospitalist or the intensivist is often involved because they keep getting readmitted. Prior to us doing so much NIV, I don't think that discussion was happening. To Ariel's [Berlinski] point, it was sort of one person made the decision that this patient needed a trach, and it wasn't widely discussed. Another comment I have is that 15 or 20 years ago now, we used to use Olympic buttons in the decannulation process because of some of the comments you brought up about even in a pediatric airway, a tracheostomy of the smallest size is taking up $50 \%$ of the lumen. But it seemed to fall out of favor, and I'm not sure why it did, because you could get some pretty small sizes of those. I'm curious as to what your thoughts are on that.
Watters: We've looked into the Olympic buttons recently for certain patients. They don't come small enough for kids under the age of 2 that you're trying to decannulate; they just don't make them. I think our main fear is that they're going to go into the airway as a foreign body. I would generally not recommend them in small children, which unfortunately are the population we are concerned about the capped tracheostomy taking up some much space in the airway.

Walsh: It doesn't look like by the data that we actually decannulate anybody before 2 anyway, so it might actually work out.

\section{Watters: That's very true.}

Cheifetz: Karen, that was a great presentation, thank you. I want to go back to the theme of Ariel's first question and your comment about the timing of tracheostomy. You showed some nice data on the costs and complications of tracheostomy. But, when we think about trachs, including the comments that have already been made, these patients are often in the ICU for a long time and are often extubated 3 or 4 times before everyone accepts the fact that the patient needs a trach. So the data presented do not take into account the costs of waiting to trach and also the potential morbidity of waiting. I do not have the answers, but what we need to get to is a determination of the right timing for tracheostomy. I throw this issue to you, as well as to our pulmonology friends. Howard [Panitch] and Dennis [Stokes], what do you think? Do we wait too long? Should we be proceeding with trachs earlier for those patients who clearly need it?

Watters: I think in a lot of situations, we do wait too long. I think in some situations, a lot of that is due to social issues around caring for the child. In a lot of cases, the family isn't ready to have a child with a trach. 
That often prolongs it. So, if you put a trach in this child-I know they're taking up a bed-where are they going to go? Perhaps the child is in foster care or the child can't go home, so we have to know that the child can be taken care of with the trach in. I do agree; I think in a lot of cases, we are waiting far too long.

Cheifetz: I agree that sometimes the families are not ready, but it often comes back to us. Maybe we broach the concept so late in the process, and the parents/family are not ready simply because we were not ready. Maybe we don't raise this option early enough in an admission, as is more often done in the adult world. Again, I do not know the answer but am simply raising this issue to provoke thought and discussion on this important topic.

Watters: I think in a lot of cases, the introduction of a trach, just the conversation with the parents should start earlier. Just to plant the seed. Also, this is a side comment, but we started introducing trach teaching to families now even a week or two before the trach is actually placed, and it's been shown that the sooner you start doing that, the sooner you get the child with a new trach out of the hospital.

Panitch: Getting back to Ariel's point about the importance of a multidisciplinary discussion about tracheostomy and timing, the group that we struggle with are those children with cerebral palsy patients who obviously have issues with upper-airway obstruction and who may aspirate, and the risk/benefit in that population. Many of those patients have been managed for years without a tracheostomy, and then you trade perhaps one hospitalization for aspiration pneumonia per year for $100 \%$ bacterial colonization of the airway and frequent episodes of tracheitis. How do you handle that group; upper-airway and chronic lung disease I think are pretty straightforward, but with that group, it's hard.

Watters: I agree those children have such a high risk of recurrent hospitalizations. I know that in our institution how they usually end up getting a trach is on one of those admissions, and they can't be extubated. Then they finally need a trach, but I think that whole topic should be broached a lot sooner, probably in the out-patient setting. For the families, it changes the care of the patient entirely; they're going to need nursing care at home to take care of this child, but perhaps that's better than ending up in the ICU 4 or 5 times a year on a ventilator because of recurring pneumonias.

Stokes: The other thing is I want to congratulate you on this collaborative, I think that approach, most of us who work in cystic fibrosis are really familiar with the value of this kind of feedback about how your center compares to others. Is that an organization that any hospital can join? It's something we would be interested in.

Watters: The Global Tracheostomy Collaborative is open to any institution to join, and we encourage institutions to join. It really is a multidisciplinary group; the members come from respiratory, otolaryngology, pulmonary, speech/language-it's truly multidisciplinary. Over the last year or so, we've done a lot of work that hopefully in time and as our database matures, it will be a very rich source of data.

Sweet: I think there are 2 pieces to this conversation. The one group of patients for whom trach actually may be a tool to get them out of the ICU, and it seems to me that we're not framing that well with our patients. We're framing it that tracheostomy may appear to be a long-term intervention as opposed to a tool, and I think that messaging needs to be something we de- velop as a care team. The second aspect is the decision-making for the patient for whom it's clear the trach is going to be a long-term intervention. Pulling together the care teams, including palliative care, to make that decision is a critical part of what needs to happen. I think it's only happening more consistently in the recent past. Those are my perspectives on the decision-making and ethics of tracheostomy. I also want to circle back to your decannulation discussion because there were 2 pieces of that I wanted to be clear on. First, in your video, you didn't show the trach tube coming out to assess the airway, and I wanted to make sure that is included in the airway evaluation.

Watters: Yes, the tracheostomy does of course come out of the airway on every direct laryngobronchoscopy; I just wanted to get on to the next slide. Obviously, routinely we do an initial pass to see how the trach is sitting in the airway, then the trach is removed and the airway is examined without the trach in situ. We want to make sure there isn't superstomal collapse or malacia. It's a very important part of the upper-airway examination.

Sweet: The second question has to do with the utility of a sleep study. What's the false negative rate? Since you've got the tube obstructing the airway by its presence, you may increase the likelihood of getting a sleep study that forces you to defer decannulation. How do you manage and think about that scenario?

Watters: That's a very difficult situation, because clearly, based on sleep study, you have a report saying the child is obstructing. The family is telling you that the child sleeps fine at home, and they're on a saturation monitor at home. It is a balance of the benefit of getting the trach out versus the risk of taking it out when the child is not ready and having to put it back in. I think that in general, if the sleep 
study is favorable, it is a very high predictor of successful decannulation. There have been situations where I will say that due to the parental pressure, providing you think it's safe, that you will put the child in the ICU and take the trach out and see how they do overnight. I'm not recommending that should be done in every case, but from personal experience, I have done this in select patients with success.

Sweet: That may be the situation where you would try and orchestrate a sleep study without the trach in place.

\section{Watters: Yes.}

Fedor: I have a question on a related topic. We have a lot of choices with trach tubes these days; we have flexed ends, cuffed, uncuffed, water cuff, air cuff, and standard, and each of those carries a complication and has patient safety issues. Would you comment on that?

Watters: We standardly use the Bivona pediatric trach tubes just because they're softer, and if you need a cuffed tube, the tight-to-shaft one by Bivona is much easier to put in and take out. Now you can also customize any size trach - we actually carry FlexTend tracheostomy tubes as a standard stocked item in our hospital, but we typically only use them in the small infants with chubby short necks. As the child gets older and is more mobile, they have a tendency to pull out the FlexTend tubes a lot more. Obviously, any trach tube has risks of causing pressure; it's a foreign body that's moving all the time and can cause granulation or collapse to the underlying tracheal tissue and cartilage.

Fedor: In our chronic vent/trach unit, we tend use the FlexTend tubes almost exclusively because they can participate more in their rehab, they're much more mobile in positioning, and our OT/PT [open tracheostomy/percuta- neous tracheostomy] folks really prefer to work with those types of trachs in general because it gives them more flexibility.

Watters: Even in older children, too?

Fedor: Our vent/trach rehab hospital takes kids from several months all the way up to adulthood. We do not generally use the FlexTend tubes in the older patients; usually they're used in the kids younger than $5 \mathrm{y}$ of age.

Berlinski: Can you comment about nebulizer therapy treatments that are applied with a tracheostomy mask, and how does that influence or create complications for the stoma by increasing moisture?

Watters: That's a very good point that you bring up, the increased moisture around the trach. I would say that we do see children on occasion with allergic-like reactions from the nebulizers. An alternative method to try and prevent that might be to give the medication through a spacer connected directly to the trach tube.

Berlinski: Probably using a pMDI [pressurized metered-dose inhaler] with a spacer would be one option. The other would be a direct connection to the trach rather than using a mask.

Panitch: I have 2 questions in regards to that: first, your feelings about using things like Hydrosorb that maintain wetness around the trach vs either no padding or just split gauze?

Watters: We typically use either split dry gauze or Mepilex Lite. We used to use Exu-Dry a lot, but we find that it gets very hard and crusty and can actually tear the skin. In kids who have problems with granulation around the stoma, we actually have been using a lot of Mepilex AG lately.
It has really changed our management of granulomas around the stoma.

Panitch: My second question goes back to the issue about timing of tracheostomy placement and what happens afterwards. In my institution, when a child receives a tracheostomy, there's an 8-week program the family goes through in terms of training, whether or not there's a ventilator attached to the other end of the tube. Before we will discharge a child with a tracheostomy, the parents have to demonstrate their ability to suction the airway, change the tube, recognize medical emergencies, etc. That's part of our discussion with the family; this will extend the hospitalization that long. Would you comment about the post-trach training program and how that relates to post-hospital morbidity and mortality?

Watters: That's a very good point, because I know in some other hospitals - one of my colleagues works in Dallas, and they're only allowed to change the trach on a weekly basis. So that delays discharge considerably; I think it's 6 weeks before the child can go home. My feeling and what we practice in Boston Children's is that once the first trach change has been safely performed, the parents immediately start to get trained on changing the trach. Depending on how enthusiastic and well educated they are, sometimes they're even changing the trach on a daily basis. From our experience, the sooner you start educating the parents, the sooner they become more comfortable, and it gets to the point where they are very proficient at changing it, and their comfort level increases-some parents can change it 5 times a week during the training process. If everyone is happy with the parents' trach care, then they're ready to go home, and the hospital stay has been dramatically reduced. I will say we've only brought that in in the last few years. Early ed- 
ucation, more frequent tube changing is better.

Walsh: I'd like to add to that a little bit. We've also at discharge asked the parents to change the trach more frequently so that they get used to doing it. So then if an emergency arises, they know how to do it. Asking them to change it more frequently and then tapering it out eventually is a new strategy for us to get caregivers, and even the child, more comfortable with the process.
Watters: We sometimes run into other issues like insurance not giving them enough trachs, but if you write enough letters to justify that they need them, it usually works out.

* Wagler: As for trach changes and education for family members, our normal protocol consisted of initial change by the RT [respiratory therapist] within 5-7 d and then continuing weekly. With this protocol, family instruction and increasing their comfort level with the trach change became problematic due to the patient's length of hospital stay. You commented you would do trach changes daily if necessary. Any complications with that frequent of a trach change?

Watters: No, once we're happy the stoma has matured, it's safe to be changed.

\footnotetext{
* Angel Wagler RRT, invited discussant. Ms Wagler is affiliated with Teleflex.
} 